\title{
Optimal process design for the polygeneration of SNG, power and heat by hydrothermal gasification of waste biomass: Process optimisation for selected substrates
}

\author{
Martin Gassner $^{\mathrm{a}}$, Frédéric Vogel ${ }^{\mathrm{b}}$, Georges Heyen $^{\mathrm{c}}$, François Maréchal $^{\mathrm{a}}$ \\ ${ }^{a}$ Industrial Energy Systems Laboratory, Ecole Polytechnique Fédérale de Lausanne \\ CH - 1015 Lausanne, Switzerland \\ ${ }^{\mathrm{b}}$ Laboratory for Bioenergy and Catalysis, Paul Scherrer Institut, Villigen \\ $\mathrm{CH}-5232$ Villigen, Switzerland \\ ${ }^{c}$ Laboratoire d'Analyse et Synthèse des Systèmes Chimiques, Université de Liège \\ B - 4000 Liège, Belgium
}

Energy and Environmental Science (2011), doi:10.1039/c0ee00634c

\begin{abstract}
Based on a previously developed thermo-economic process model, this paper presents a detailed design study for the polygeneration of Synthetic Natural Gas (SNG), power and heat by catalytic hydrothermal gasification of biomass and biomass wastes in supercritical water. Using multi-objective optimisation techniques, the thermodynamic and thermo-economic performances of all candidate configurations from a general process superstructure are optimised with respect to SNG and electricity cogeneration and its associated investment cost, production cost and plant profitability. The paper demonstrates how both the optimal system configuration, its operating conditions and performances depend on the available technology, catalyst lifetime, process scale and the characteristics of the processed substrate.
\end{abstract}

\section{Nomenclature}

\section{Abbreviations}

GT Gas turbine

$M E R$ Minimum energy requirement

NGCC Natural gas combined cycle

$P O X$ Partial oxidation

SNG Synthetic natural gas

$V L \quad$ Vapour-liquid

\section{Greek letters}

$\Delta h^{0} \quad$ Lower heating value

$\Delta \tilde{h}_{r}{ }^{0} \quad$ Standard heat of reaction

$\Delta k^{0} \quad$ Exergy value

$\varepsilon \quad$ Energy efficiency

$\mathrm{kJ} \mathrm{kg}^{-1}$

$\eta \quad$ Exergy efficiency

$\Phi \quad$ Moisture

Roman letters

A Absorption factor

$b \quad$ Cost exponent 


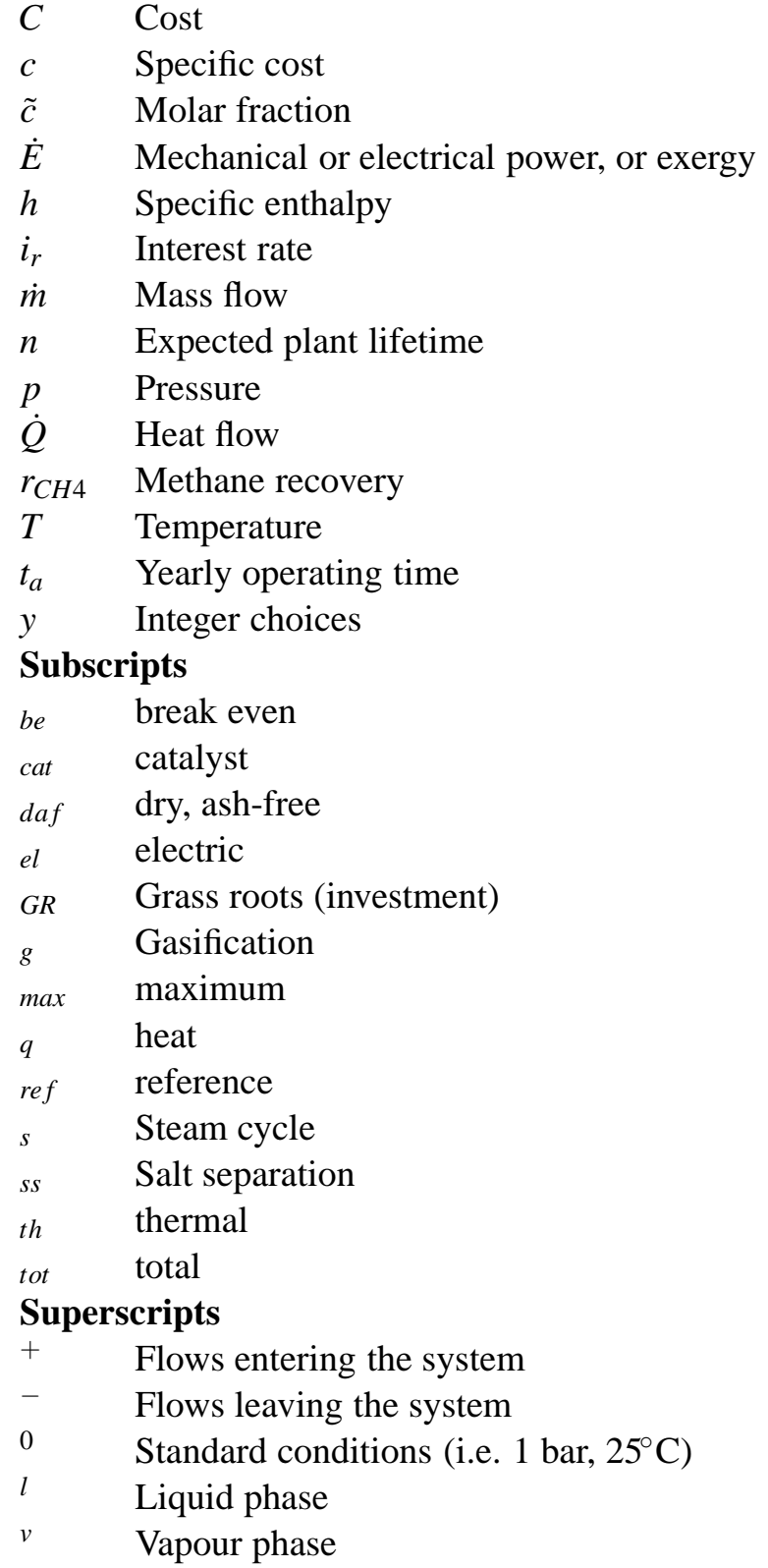

\section{Introduction}

Hydrothermal gasification of wet lignocellulosic biomass and biomass wastes in supercritical water to methane and carbon dioxide is a promising, emerging pathway for the production of synthetic natural gas (SNG). Unlike conventional technologies, it does not suffer from an incomplete conversion like biomethanation, and may efficiently convert wet feedstock due to a sharply decreasing specific and latent heat demand of water at supercritical pressure that rules out conventional production by gasification and methanation [1]. Waste biomass such as manure, sewage sludge and food processing residues, are substrates that are largely unused and inherently cheap. A priori, its conversion to energy services is sustainable due to the waste treatment character of such facilities. In Switzerland, these substrates sum up to almost half of the total sustainable biomass potential and represent the major share of today's unused capacity [2].

Catalytic hydrothermal gasification targets the conceptual overall conversion of biomass as exemplified by Equation (1) without prior endothermal decomposition at high temperature into a $\mathrm{H}_{\mathbf{L}}$ - and 


\section{Broader context}

Biomass is a renewable, yet scarce resource since land is limited. Claimed by many as future feedstock to produce goods and provide energy, there is important concern about intensified farmland and forest exploitation and its inherent competition with food production.

Agricultural, industrial and municipal residues and wastes often hold a large share of a countrys unused non-fossil, carbonaceous energy resources and are not subject to the trilemma between food supply, energy supply and environmental protection. However, these potential resources are difficult to valorise since they are highly diluted and may contain harmful species for bacteria and catalysts, which greatly handicaps its biological or conventional thermochemical conversion to more versatile energy vectors than heat. Hydrothermal gasification allows for circumventing these obstacles by exploiting the advantageous properties of water at supercritical conditions.

Our research shows that the process design represents both a major challenge and opportunity for the successful development of energy- and cost-efficient technology. Using systematic methodology based on process modelling, integration and optimisation, it demonstrates how the design should adapt to constraints imposed by current technological limitations and feedstock impurities, and concludes that optimised configurations allow for saving up to $24 \%$ of Switzerlands greenhouse gas emissions with currently unused resources.

CO-rich producer gas [3]:

$$
\mathrm{CH}_{1.35} \mathrm{O}_{0.63}+0.3475 \mathrm{H}_{2} \mathrm{O} \rightarrow 0.51125 \mathrm{CH}_{4}+0.48875 \mathrm{CO}_{2}, \quad \Delta \tilde{h}_{r}{ }^{0}=-10.5 \mathrm{kJmol}_{\text {biomass }}^{-1}
$$

This 'direct' conversion can be achieved by hydrolysing the biomass in a liquid aqueous phase at high pressure (250-350 bar, $\left.200-380^{\circ} \mathrm{C}\right)$, precipitation and recovery of the inorganics as salts at supercritical water conditions $\left(400-550^{\circ} \mathrm{C}\right)$, and gasification of the hydrolysis products over a $\mathrm{Ni}$ - or $\mathrm{Ru}$-based catalyst $\left(400^{\circ} \mathrm{C}\right)$. The successful development of such a process is yet challenging and has to address several critical issues. On the one hand, an efficient and robust catalyst is required and its fast deactivation is to be prevented [4]. Related to this is the design of a separation device to precipitate and remove the salts, including in particular those poisoning the catalyst, whose recovery further enables for their reuse as nutrients in concentrated form [5-8]. A third challenge is the design of an energy- and cost-efficient plant through a sound process integration. Around $80 \%$ of the total mass flow is accompanying bulk water that multiplies the actual heat transfer requirements of the reacting species. These requirements are balanced by combusting gas that is withdrawn from the product. Electricity may not only be generated from excess heat, but also from the exergy potential of the hot gasification product at supercritical conditions. The plant performance is thus very sensitive to the energy integration, and advantage can be taken from combining the separation, heat supply and energy recovery systems.

In the first part of this design study [3], these possibilities are systematically analysed and a thermoeconomic process model for a superstructure of promising flowsheet alternatives is developed. The objective of the present paper is to explore these options with multi-objective optimisation techniques and to determine the best flowsheets with respect to available technology, catalyst deactivation, plant scale and various types of feedstock.

\section{Methodology}

\subsection{Conceptual process design}

The thermo-economic process model [3] is developed following a systematic methodology for the conceptual design of thermochemical production of fuels from biomass [9]. Similar to a classical design procedure, the analysis of raw material characteristics, product specifications and feasible production pathways allows for identifying suitable technology for the process unit operations and energy recovery that are assembled in a process superstructure. A decomposition-based modelling approach is then 
Table 1: Properties of the candidate feedstocks that are dried or diluted to a pumpable slurry with a total solids content of $20 \% \mathrm{wt}$

\begin{tabular}{|c|c|c|c|c|c|c|c|c|c|c|c|c|}
\hline \multirow[b]{3}{*}{ Feedstock } & \multicolumn{3}{|c|}{ Proximate analysis } & \multicolumn{5}{|c|}{ Ultimate analysis } & \multicolumn{2}{|c|}{ St. coeff. (Eq. 1) } & \multicolumn{2}{|c|}{ Sustainable pot. $^{\mathrm{a}}$} \\
\hline & $\Phi$ & ash & $\Delta h^{0}$ & $\mathrm{C}$ & $\mathrm{H}$ & $\mathrm{O}$ & $\mathrm{N}$ & $\mathrm{S}$ & $\mathrm{CH}_{4}$ & $\mathrm{CO}_{2}$ & $\mathrm{CH}[2]$ & $\mathrm{CH}[16]$ \\
\hline & $\%$ wt & $\% \mathrm{wt}_{d r y}$ & $\mathrm{MJ} \mathrm{kg}_{d a f}^{-1}$ & \multicolumn{5}{|c|}{$\% \mathrm{wt}_{d a f}$} & - & - & \multicolumn{2}{|c|}{$\mathrm{W} \mathrm{cap}^{-1}$} \\
\hline Wood[13] & 50 & 0.6 & 18.6 & 51.1 & 5.8 & 42.9 & 0.2 & $\mathrm{n} / \mathrm{a}$ & 0.51 & 0.49 & 161 & 327 \\
\hline Sewage sludge, digested ${ }^{\mathrm{b}}$ & 95 & 47.8 & 19.2 & 49.2 & 6.0 & 37.6 & 7.2 & $\mathrm{n} / \mathrm{a}$ & 0.54 & 0.46 & \multirow{2}{*}{22} & \multirow[b]{2}{*}{26} \\
\hline Sewage sludge, undigested ${ }^{b}$ & 95 & 36.9 & 20.6 & 50.6 & 6.5 & 34.1 & 8.8 & $\mathrm{n} / \mathrm{a}$ & 0.57 & 0.43 & & \\
\hline Pig manure[17] & 97 & 24.9 & 21.2 & 48.0 & 8.3 & 36.1 & 7.0 & 0.6 & 0.62 & 0.38 & 92 & 98 \\
\hline Coffee grounds ${ }^{c}$ & 50 & 0.3 & 26.0 & 60.1 & 8.5 & 29.6 & 1.6 & 0.2 & 0.62 & 0.38 & 35 & 32 \\
\hline Lignin slurry $^{\mathrm{d}}$ & 75 & 0.6 & 23.4 & 55.8 & 8.2 & 36.0 & $\mathrm{n} / \mathrm{a}$ & $\mathrm{n} / \mathrm{a}$ & 0.60 & 0.40 & 40 & 57 \\
\hline Microalgae $\mathrm{e}^{\mathrm{e}}$ & 87 & 12.5 & 25.3 & 57.7 & 7.6 & 25.3 & 8.1 & 1.3 & 0.61 & 0.39 & - & - \\
\hline
\end{tabular}

a Total sustainable biomass potential for Switzerland: 81.9/126 PJ year ${ }^{-1}$ (conservative[2]/optimistic[16] estimates) for a population of approx. 7.4 Mio (2005). Distribution to substrates is based loosely on the reported categories [2]. The potentials are reported as energy intensity W cap ${ }^{-1}$ that corresponds to the yearly average of the energy potential per capita expressed as (W year) year ${ }^{-1} \mathrm{cap}^{-1}\left(=365 \cdot 24 \cdot 60 \mathrm{~J}\right.$ year $\left.{ }^{-1} \mathrm{cap}^{-1}\right)[18]$

$\mathrm{b}$ internal data [19] for a mixture of wet primary and secondary sludges. Ash content is based on digested sludge from ECN [20, ID 2810], from which the one for undigested sludge is determined via a digester mass balance [19]

c ID 2190 from ECN [20]

${ }^{\mathrm{d}}$ residue of ethanol production from lignocellulosic biomass [21]

e Phaeodactylum tricornutum [22]

adopted to systematically develop candidate flowsheets. First, the thermochemical conversion and the energy requirements of the process units are computed in energy-flow models that are developed in flowsheeting software [10]. The combined mass- and energy integration is then performed by mixed integer linear programming, in which both the material flows defined by the superstructure and the heat cascade - that represents the heat exchanger network - act as constraints [11]. Considering waste and intermediate product streams as fuel to supply the required heat, the combined SNG, heat and power production is optimised with respect to operating cost. For the so-determined flowsheet, all the equipment is rated with design heuristics and laboratory and pilot plant data to estimate the investment required to meet the thermodynamic design target. This model decomposition is particularly appropriate for conceptual process design since it allows for efficiently generating a set of optimal process configurations with an evolutionary, multi-objective optimisation algorithm.

\subsection{Multi-objective process optimisation of all flowsheet alternatives and candidate sub- strates}

Multi-objective optimisation techniques have been introduced in the conceptual design of energy conversion systems in order to provide an enlarged set of candidate solutions to a design problem that is characterised by several conflictive objectives such as efficiency, cost and environmental impact. Due to their ability of handling non-linear and non-continuous objective functions, evolutionary algorithms have thereby proven as a robust method for solving complex system optimisation problems. Using such an algorithm [12], the present paper investigates the combined SNG and power cogeneration potential (Section 3) and the optimal thermo-economic plant design (Section 4) for all identified candidate flowsheet configurations. This detailed design study is carried out for the example of wood feedstock with the properties given in Table 1. Although wood is not the most attractive substrate for hydrothermal gasification due to increasing resource competition and price, it is considered in this part of the analysis in order to provide a direct comparison of the performance with SNG production by conventional gasification and methanation that has been studied with the same feedstock and methodology [13-15].

In order to investigate the influence of the feedstock characteristics on the process design, the cogeneration potential and thermo-economic optimisations are repeated in Section 5 for the selected representative candidate substrates of Table 1. Contrary to the detailed design study of Sections 3 and 4 in which the Pareto front of each major flowsheet configuration is individually generated in a distinct run, the choice of the best configuration is thereby left to the algorithm to limit the amount of data to be 


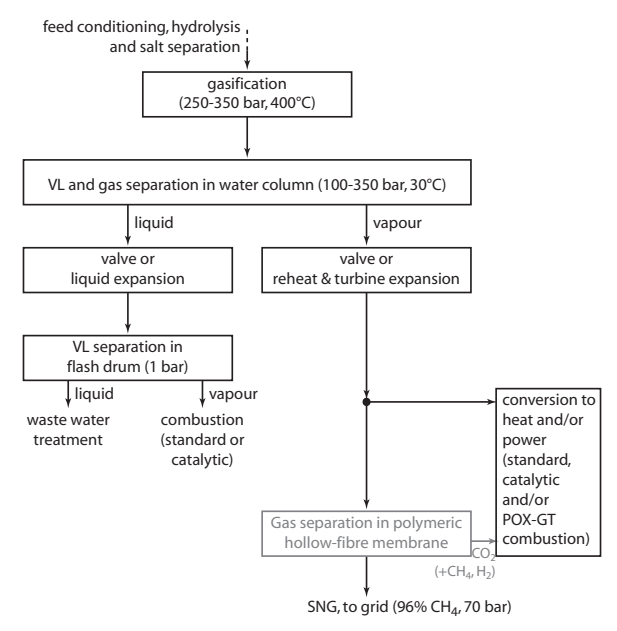

(a) Configurations (1) and (1m)

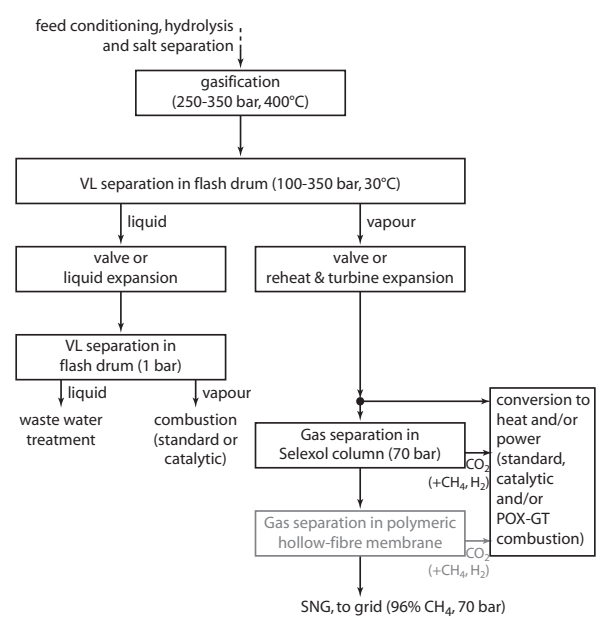

(b) Configurations (2) and (2m)

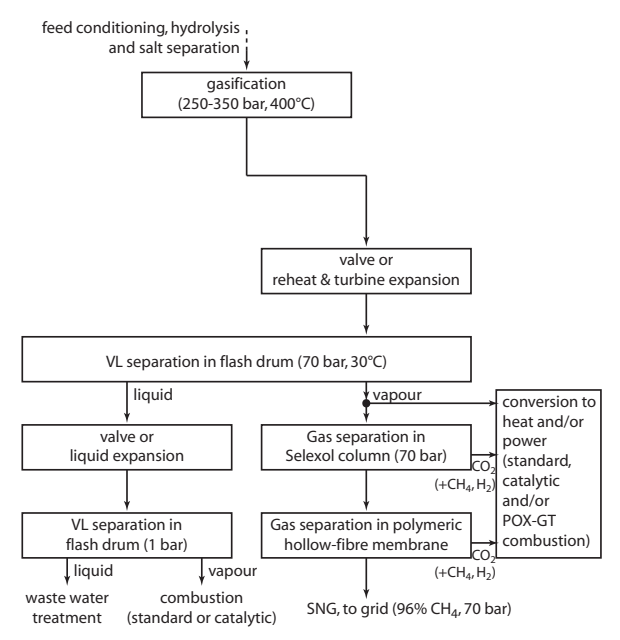

(c) Configuration (3m)

Figure 1: Major flowsheet configurations for combined product separation and expansion

discussed. The optimisations have been carried out in 10'000 (Sections 3 and 4) and 20'000 iterations (Section 5) by parallel computing on a high performance cluster [23].

\subsection{Flowsheet alternatives}

In order to explore and optimise the performance of the different process design alternatives discussed in the process analysis [3], individual optimisations of the major flowsheet configurations with respect to the product separation are carried out. These are illustrated in Figure 1, i.e.:

(1) vapour-liquid (VL) and gas separation in a water column at high pressure

(1m) same as (1), but with an additional membrane separation step at grid pressure for final purification

(2) bulk VL separation in a high pressure flash drum and gas separation at grid pressure by selexol absorption

(2m) same as (2), but with an additional membrane separation step at grid pressure for final purification, and

(3m) no high pressure separation, but both VL and gas separation by a flash drum and selexol absorption at grid pressure followed by a membrane separation step at grid pressure for final purification.

While the use of membrane technology as an additional downstream separation step at grid pressure to allow for the selective removal of hydrogen is mandatory in case (3), it has also been identified as promising for flowsheets that include a separation step at high pressure (i.e. options $(1 \mathrm{~m})$ and $(2 \mathrm{~m})$ ), since it relaxes the required methane purity in the bulk separation. All these alternatives are optimised without and with partial oxidation gas turbine technology fed with the different candidate fuels [3]. In all configurations, the use of a steam Rankine cycle with several utilisation levels for recovering excess heat as electrical power is included in the decision variables of the optimisation. The principal fixed operating conditions and a complete list of the identified decision variables for all optimisation runs is given in Table 2. The general assumptions and other operating conditions are considered at the default values [3].

\subsection{Thermodynamic property models}

Due to the processing in supercritical water, the biomass gasification and separation processes (1)-( $3 \mathrm{~m})$ for the polar mixture of $\mathrm{H}_{2} \mathrm{O}, \mathrm{CO}_{2}$ and $\mathrm{CH}_{4}$ are operated in a very large range of thermodynamic conditions. In the process modelling [3], special care has therefore been taken to accurately represent the enthalpy-temperature profiles and vapour-liquid equilibria throughout the process. 
Table 2: Principal fixed operating conditions and decision variables for optimisation. General assumptions and other operating conditions are at their default values of the process model [3]

\begin{tabular}{|c|c|c|c|c|}
\hline Section & Operating conditions & & Unit & Value/Range \\
\hline \multirow[t]{2}{*}{ Pretreatment } & Total solids content of diluted feed & & $\%$ wt & 20 \\
\hline & Process pressure & $p_{\text {tot }}$ & bar & {$\left[\begin{array}{lll}250 & 350\end{array}\right]$} \\
\hline \multirow[t]{6}{*}{ Salt separation } & Inlet temperature & $T_{s s, i n}$ & ${ }^{\circ} \mathrm{C}$ & 350 \\
\hline & Maximum temperature & $T_{s s, \max }$ & ${ }^{\circ} \mathrm{C}$ & {$\left[\begin{array}{lll}430 & 550]\end{array}\right.$} \\
\hline & Internal heat decrease & $\Delta T_{s s, i n t}$ & ${ }^{\circ} \mathrm{C}$ & {$[1070]$} \\
\hline & $\Delta T$ at bottom & $\Delta T_{s s, \text { bottom }}$ & ${ }^{\circ} \mathrm{C}$ & {$\left[\begin{array}{lll}10 & 70\end{array}\right]$} \\
\hline & $\Delta T$ at top & $\Delta T_{s s, t o p}$ & ${ }^{\circ} \mathrm{C}$ & {$\left[\begin{array}{lll}10 & 70\end{array}\right]$} \\
\hline & Organic loss in salt brine & & $\%$ & 10 \\
\hline Gasification & Outlet temperature & $T_{g, \text { out }}$ & ${ }^{\circ} \mathrm{C}$ & 400 \\
\hline \multirow[t]{3}{*}{ Water column } & Pressure & $p_{\text {hp sep }}$ & bar & {$\left[\begin{array}{lll}100 & 350\end{array}\right]^{\mathrm{a}}$} \\
\hline & Equilibrium stages & $N_{s, H 2 O}$ & - & [3 5] \\
\hline & $\mathrm{CH}_{4}$ purity $^{\mathrm{b}}$ & $\tilde{c}_{C H 4, h p, o u t}$ & $\% \mathrm{~mol}$ & {$\left[\begin{array}{ll}80 & 95\end{array}\right]$} \\
\hline \multirow[t]{3}{*}{ Selexol column } & $\mathrm{CH}_{4}$ recovery & $r_{\mathrm{CH} 4, \mathrm{sel}}$ & $\%$ & [95 99] \\
\hline & Absorption factor & $A_{\text {sel }}$ & - & {$\left[\begin{array}{ll}1 & 1.8\end{array}\right]$} \\
\hline & $\mathrm{CH}_{4}$ purity ${ }^{\mathrm{b}}$ & $\tilde{c}_{C H 4, \text { sel,out }}$ & $\% \mathrm{~mol}$ & [90 96] \\
\hline SNG membrane & Material $^{\mathrm{b}}$ & $y_{m e m b}$ & integer & {$\left[\begin{array}{ll}1 & 2\end{array}\right]$} \\
\hline \multirow[t]{3}{*}{ Power recovery } & Vapour phase & $y_{\text {prec }}^{v}$ & integer & {$\left[\begin{array}{ll}0 & 1\end{array}\right]$} \\
\hline & Liquid phase & $y_{\text {prec }}^{l}$ & integer & {$\left[\begin{array}{ll}0 & 1\end{array}\right]$} \\
\hline & Reheat temperature of vapour & $T_{g, s}$ & ${ }^{\circ} \mathrm{C}$ & {$\left[\begin{array}{lll}300 & 600\end{array}\right]$} \\
\hline \multirow[t]{3}{*}{ Rankine cycle } & Steam production pressure & $p_{s, p}$ & bar & {$\left[\begin{array}{ll}20 & 120\end{array}\right]$} \\
\hline & Steam superheat temperature & $T_{s, s}$ & ${ }^{\circ} \mathrm{C}$ & {$[300550]$} \\
\hline & Intermediate utilisation level & $T_{s, u}$ & ${ }^{\circ} \mathrm{C}$ & {$\left[\begin{array}{lll}50 & 250\end{array}\right]$} \\
\hline \multirow[t]{3}{*}{ POX gas turbine } & Pressure & $p_{P O X}$ & bar & {$\left[\begin{array}{ll}5 & 30\end{array}\right]$} \\
\hline & Fuel choice $^{c}$ & $y_{\text {fuel }}$ & integer & {$\left[\begin{array}{ll}1 & 7\end{array}\right]$} \\
\hline & Additional steam per fuel $i$ & $r_{f i, H 2 O}$ & $\mathrm{~kg} \mathrm{~kg}^{-1}$ & {$\left[\begin{array}{ll}0 & 1\end{array}\right]$} \\
\hline \multirow[t]{2}{*}{ NG grid specifications } & $\mathrm{CH}_{4}$ purity & $\tilde{c}_{C H 4, \text { grid }}$ & $\%$ & 96 \\
\hline & Grid pressure & $p_{\text {grid }}$ & bar & 70 \\
\hline
\end{tabular}

${ }^{\text {a }}$ Process pressure $p_{t o t}$ restricts maximum limit

b Only used in case of final SNG-upgrading with a polymeric membrane. Material choice (properties[13]): 1: cellulose acetate, 2: polysulfone

c Candidate fuels: 1: (crude) SNG, 2: recovered depleted stream from flash, 3: membrane permeate, combinations: 4: $1 \& 2$,

5: 1\&3, 6: 2\&3, 7: all

Several approaches to evaluate the thermodynamic properties of these fluids have been investigated $[3,15]$ and a hybrid approach has finally proven suitable. A homogeneous equation of state for the $\mathrm{H}_{2} \mathrm{O}-$ $\mathrm{CO}_{2}-\mathrm{CH}_{4}$ system developed by Duan et al. $[24,25]$ has been extended by similarity with the equation of Lee and Kesler [26] to include the minor species[27]. Above $250^{\circ} \mathrm{C}$, this model is used to calculate the vapour-liquid equilibrium and assures coherency in the critical zone. Below $250^{\circ} \mathrm{C}$, however, Duan's equation of state looses both accuracy and robustness and his heterogeneous solubility model [28, 29] regressed[15] on ternary data[30] is used instead. Throughout the process, enthalpy is consistently evaluated with Lee and Kesler's equation since Duan's model shows severe deviation from reliable data for pure water.

\subsection{Performance indicators}

\subsubsection{Thermodynamic performance.}

Throughout the analysis, the thermodynamic performance of process flowsheets is discussed regarding the conversion efficiencies of the products, i.e. SNG (2), electricity (3) and heat (4):

$$
\varepsilon_{S N G}=\frac{\Delta h_{S N G}^{0} \dot{m}_{S N G}^{-}}{\Delta h_{\text {biomass }}^{0} \dot{m}_{\text {biomass,daf }}^{+}}
$$




$$
\begin{aligned}
\varepsilon_{e l} & =\frac{\dot{E}^{-}}{\Delta h_{\text {biomass }}^{0} \dot{m}_{\text {biomass }, \text { daf }}^{+}} \\
\varepsilon_{t h} & =\frac{\dot{Q}^{-}}{\Delta h_{\text {biomass }}^{0} \dot{m}_{\text {biomass }, \text { daf }}^{+}}
\end{aligned}
$$

and the overall energy $\varepsilon$, exergy $\eta$ and 'chemical' $\varepsilon_{c h e m}$ efficiencies defined as, respectively:

$$
\begin{aligned}
\varepsilon & =\frac{\Delta h_{S N G}^{0} \dot{m}_{S N G}^{-}+\dot{E}^{-}+\dot{Q}^{-}}{\Delta h_{\text {biomass }}^{0} \dot{m}_{\text {biomass,daf }}^{+}+\dot{E}^{+}} \\
\eta & =\frac{\Delta k_{S N G}^{0} \dot{m}_{S N G}^{-}+\dot{E}^{-}+\dot{E}_{q}^{-}}{\Delta k_{\text {biomass }}^{0} \dot{m}_{\text {biomass,daf }}^{+}+\dot{E}^{+}} \\
\varepsilon_{\text {chem }} & =\frac{\Delta h_{S N G}^{0} \dot{m}_{S N G}^{-}+\frac{1}{\eta_{N G C C}} \frac{\Delta h_{S N G}^{0}}{\Delta k_{S N G}^{0}}\left(\dot{E}^{-}+\frac{\dot{E}_{q}^{-}}{\eta_{H P}}\right)}{\Delta h_{\text {biomass }}^{0} \dot{m}_{\text {biomass,daf }}^{+}}
\end{aligned}
$$

In these definitions, $\Delta h^{0}$ and $\Delta k^{0}$ designate the dry lower heating and exergy values, and $\dot{m}$ the mass flow of SNG and biomass. $\dot{E}, \dot{Q}$ and $\dot{E}_{q}$ represent electrical power, heat and the exergy of heat. For all hydrocarbon substrates and intermediate macromolecular groups without a strict thermodynamic definition of their enthalpy of formation and entropy, $\Delta h^{0}$ and $\Delta k^{0}$ are thereby determined with correlations [31, 32]. The superscripts ${ }^{-}$and ${ }^{+}$refer to produced and consumed services, respectively. In Eqns. (5) and (6), only the positive value of $\dot{E}$ occurs either in the numerator or denominator, while Eqns. (3) and (7) assess net electricity consumption by a negative value of $\dot{E}^{-}$. The production of heat is only useful if it is provided at a sufficient temperature level to be used locally and is considered zero otherwise.

The overall energy and exergy indicators $\varepsilon$ and $\eta$ provide a strictly physical measure of the energy conversion and its quality degradation. Yet, they do not satisfactorily assess the value of the products with respect to the efficiency of their further conversion into final energy services and competing technologies [15]. The technical value of the cogeneration products are therefore assessed in terms of the fuel-equivalent efficiency $\varepsilon_{c h e m}$, in which the net electricity balance is substituted by the equivalent amount of (synthetic) natural gas that is consumed or saved in reference technology. Aiming at a consistent weighting with efficient state-of-the-art technology, electricity is represented by a natural gas combined cycle (NGCC), and heat by electricity-driven heat pumps (HP), both with an exergy efficiency of $\eta_{N G C C}=\eta_{H P}=55 \%$. This corresponds to an energy efficiency of $\varepsilon_{N G C C}=57 \%$ and performance coefficients of 3.1 and 1.6 for electricity- and gas driven heat pumps in a district heating network with supply and return temperatures of 110 and $70^{\circ} \mathrm{C}$, respectively. From an energy systems perspective, this substitution is letigimate and leads to a consistent and technologically reasonable appraisal of the different energy vectors [33].

\subsubsection{Economic performance.}

The economic performance assessment of a process configuration is based on the specific investment costs $c_{G R}\left[\$ \mathrm{~kW}_{\text {biomass,daf }}^{-1}\right]$ :

$$
c_{G R}=\frac{C_{G R}}{\Delta h_{\text {biomass }}^{0} \dot{m}_{\text {biomass }, \text { daf }}^{+}}
$$

in which $C_{G R}$ represents the total investment from 'grass roots' determined from the detailed equipment rating and costing in the thermo-economic process model [3]. As discussed in the model description, the overall economic performance of a polygeneration plant is best based on the conversion of one unit of feedstock, and can be represented by the maximum acceptable biomass cost for the plant to break even, $C_{\text {biomass, be }}\left[\$ \mathrm{MWh}_{\text {biomass }}^{-1}\right.$. Rearranging its detailed formulation [3], $C_{\text {biomass, } b \text { is expressed }}$ by the weighted sum of the product yields $\varepsilon_{S N G}$ and $\varepsilon_{e l}$ (Eqs. 2-3) with their prices, from which the expenses related to the catalyst renewal $C_{\text {cat }}\left[\$ \mathrm{MWh}_{\text {biomass }}^{-1}\right.$, salaries $C_{\text {salaries }}\left[\$\right.$ year $\left.^{-1}\right]$, maintenance 
Table 3: Principal economic assumptions

\begin{tabular}{llcc}
\hline Parameter & & Unit & Value \\
\hline Wood price $\left(\Phi_{\text {wood }}=50 \%\right)$ & $C_{\text {biomass }}$ & $\$ \mathrm{MWh}^{-1}$ & 33 \\
Electricity price ('green') & $C_{e l}$ & $\$ \mathrm{MWh}^{-1}$ & 180 \\
SNG price ('green') & $C_{S N G}$ & $\$ \mathrm{MWh}^{-1}$ & 120 \\
Catalyst price & & $\$ \mathrm{~kg}^{-1}$ & 200 \\
Operator salary & & $\$$ year $^{-1}$ & 60 \\
Interest rate & $i_{r}$ & $\% 00$ \\
Discount period & $n$ & years & 6 \\
Yearly operating time & $t_{a}$ & $\mathrm{~h}$ & 15 \\
Reference year for $C_{G R}$ & & $\mathrm{US} \mathrm{Dollars}$ & 7690 \\
Currency & & 2006
\end{tabular}

${ }^{\text {a }}$ The amount of catalyst to be replaced is determined through its deactivation by residual, dissolved sulphur in the gasifier feed [3]

${ }^{\mathrm{b}} C_{\text {salaries }}$ is calculated assuming that 4.56 employees are required per operator and shift. The number of operators is assumed to 4 . For other production scales, an exponent of 0.7 with respect to plant capacity is used [3]

and discounted investment are subtracted:

$$
C_{\text {biomass }, \text { be }}=\varepsilon_{S N G} \cdot C_{S N G}+\varepsilon_{e l} \cdot C_{e l}+\varepsilon_{t h} \cdot C_{q}-C_{c a t}-\frac{C_{\text {salaries }}+0.05 \cdot C_{G R}+\frac{i_{r}\left(1+i_{r}\right)^{n}}{\left(1+i_{r}\right)^{n}-1} \cdot C_{G R}}{t_{a} \cdot \Delta h_{\text {biomass }}^{0} \dot{m}_{\text {biomass }, \text { daf }}^{+}}
$$

The yearly maintenance cost is thereby assumed to $5 \%$ of the initial investment $C_{G R}$ that is discounted with the capital recovery factor over the economic plant lifetime of $n$ years at an interest rate $i$ for a yearly operating time $t_{a}$. Note that the net profit obtained from the conversion of $1 \mathrm{MWh}$ of biomass is obtained by subtracting the cost for the substrate $C_{\text {biomass }}$ from $C_{\text {biomass }}$, . Table 3 summarises the principal economic assumptions and energy prices used in this work, which are based on typical values for renewable energy in Switzerland.

In our methodology for multi-objective process optimisation [9], we aim at generating an universal set of optimal process configurations that is as independent as possible from weighting parameters. For this purpose, it is appropriate to uncouple the thermodynamic and economic objectives in the thermoeconomic optimisation. Examining Equation (9), the only expenses that are not directly dependent on the thermodynamic performance are the investment and catalyst costs. In the optimisation, it is thus adequate to represent the purely economic aspects by summing up these two contributions and defining a specific investment cost $c_{G R, c a t}\left[\$ \mathrm{~kW}_{\text {biomass,daf }}^{-1}\right]$ that also includes the total expenses for catalyst renewal throughout the economic plant lifetime, i.e.:

$$
c_{G R, c a t}=c_{G R}+n \cdot t_{a} \cdot C_{c a t}
$$

\section{SNG and power cogeneration potential}

\subsection{Problem setup}

The process design for hydrothermal conversion of biomass is particularly flexible with respect to the co-production of fuel and power since the crude product expansion can be designed as an internal supercritical power cycle to efficiently convert heat into power [3]. In order to explore this trade-off, the maximum cogeneration potential is determined in a first optimisation step that targets the maximum net partial efficiencies of both SNG $\left(\varepsilon_{S N G}\right)$ and power $\left(\varepsilon_{e l}\right)$ defined in Equations (2) and (3), respectively. In order to correctly appreciate the technical value of the relative SNG and power yields, the fuel-equivalent - or chemical - efficiency $\varepsilon_{\text {chem }}$ defined by Equation (7) is used in the analysis. The influence of the available power recovery technology is highlighted by separately optimising all process configurations with and without power generation from expanding the vapour phase of the crude product and the use of a partial oxidation gas turbine. 

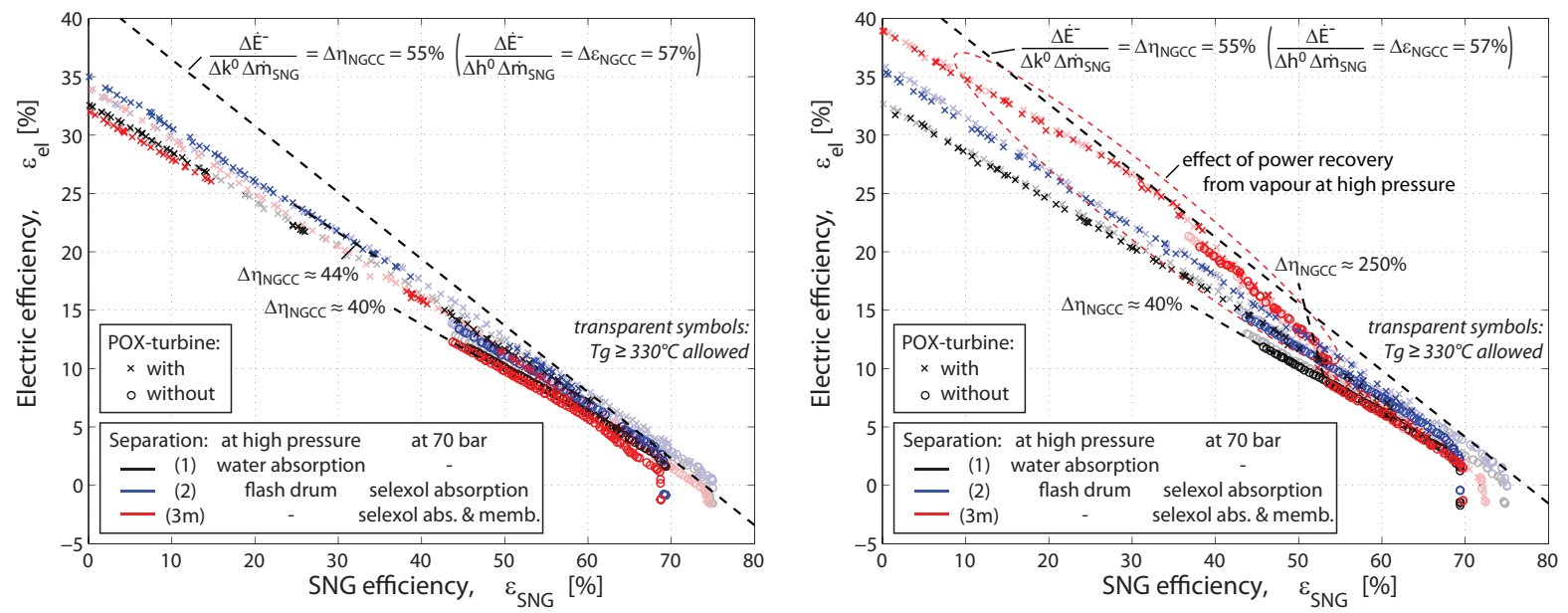

(a) Partial efficiencies (Pareto front) without power recovery (b) Partial efficiencies (Pareto front) with power recovery from from the high pressure vapour phase

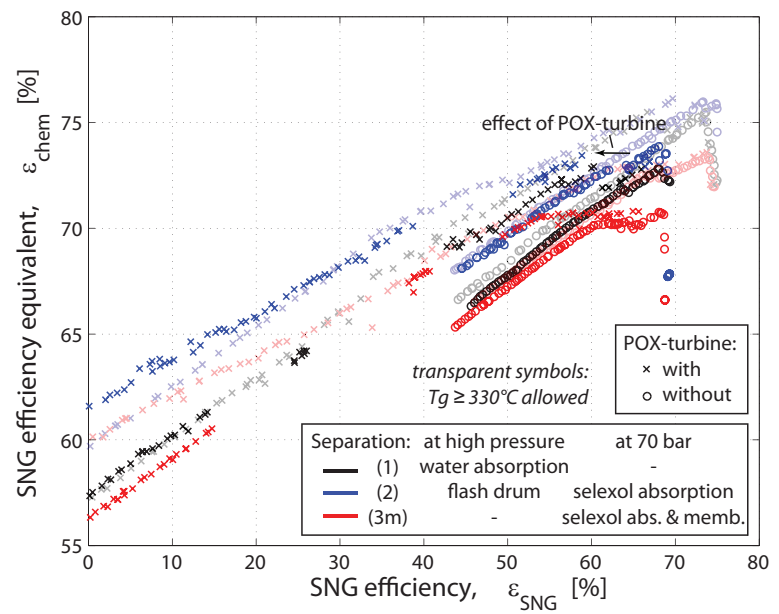
the high pressure vapour phase

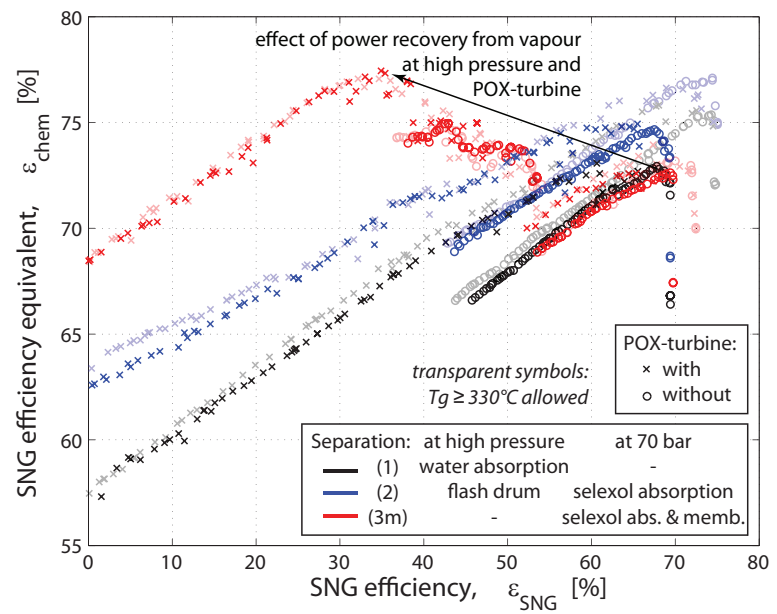

(c) Chemical efficiency without power recovery from the high(d) Chemical efficiency with power recovery from the high pressure vapour phase

pressure vapour phase

Figure 2: Maximum process efficiency for wood feedstock. Plain symbols correspond to a fixed gasification temperature $T_{g, \text { out }}$ at $400^{\circ} \mathrm{C}$, while transparent ones recall the results of an earlier optimisation for $T_{g, \text { out }} \in$ [330 400] ${ }^{\circ} \mathrm{C}$ assuming that equilibrium can still be reached [15]

\subsection{Results and discussion}

Figure 2 shows the computed SNG and electricity yields in the Pareto domain (top) and the resulting overall chemical efficiency (bottom) without (left) and with (right) power recovery by expanding the high pressure vapour phase. The dotted lines on Figure 2(a) and (b) represent the weighting applied to the relative product shares of SNG and electricity with a combined cycle at $\eta=55 \%$ (i.e. at constant and maximum $\varepsilon_{\text {chem }}$ of Figure 2(c) and (d)). Plain symbols correspond to a fixed gasification temperature $T_{g, \text { out }}$ at $400^{\circ} \mathrm{C}$, while transparent ones recall the results of an earlier optimisation for $T_{g, \text { out }} \in[330400]$ ${ }^{\circ} \mathrm{C}$ assuming that equilibrium can still be reached at such low temperatures [15]. The operating conditions and performances of the solutions that maximise $\varepsilon_{\text {chem }}$ are summarised in Table 4 . The optimisations have revealed that a supplementary membrane has only marginal influence on the thermodynamic performance, and the data for alternatives $(1 \mathrm{~m})$ and $(2 \mathrm{~m})$ are therefore omitted in this analysis.

The plots indicate that up to $70 \%$ or $40 \%$ of the biomass input can be converted into SNG or power, respectively. In between, the outputs are substitutable over a very large domain. Compared to an optimisation setup in which the gasification temperature $T_{g, \text { out }}$ has been considered as a decision variable in the range [330 400] ${ }^{\circ} \mathrm{C}$ [15], the constraint on $T_{g, \text { out }}=400^{\circ} \mathrm{C}$ imposed to avoid kinetic limitation of the 
Table 4: Design variables and performances of the optimal process configurations for wood feedstock with respect to $\varepsilon_{\text {chem }}$

\begin{tabular}{|c|c|c|c|c|c|c|c|c|}
\hline \multicolumn{3}{|c|}{ Power recovery from vapour at high pressure } & \multicolumn{3}{|c|}{ no } & \multicolumn{3}{|c|}{ yes } \\
\hline & & Unit & (1) & (2) & $(3 \mathrm{~m})$ & (1) & (2) & $(3 \mathrm{~m})$ \\
\hline \multirow[t]{24}{*}{ Design variables } & $p_{t o t}$ & bar & 332 & 350 & 348 & 337 & 345 & 350 \\
\hline & $T_{s s, \max }$ & ${ }^{\circ} \mathrm{C}$ & 439 & 435 & 431 & 432 & 438 & 526 \\
\hline & $\Delta T_{s s, \text { int }}$ & ${ }^{\circ} \mathrm{C}$ & 69 & 70 & 58 & 63 & 70 & 32 \\
\hline & $T_{s s, \text { out }}$ & ${ }^{\circ} \mathrm{C}$ & 370 & 365 & 373 & 369 & 368 & 494 \\
\hline & $\Delta T_{s s, \text { bottom }}$ & ${ }^{\circ} \mathrm{C}$ & 42 & 13 & 30 & 18 & 34 & 52 \\
\hline & $\Delta T_{s s, t o p}$ & ${ }^{\circ} \mathrm{C}$ & 33 & 32 & 15 & 39 & 16 & 10 \\
\hline & $T_{g, i n}$ & ${ }^{\circ} \mathrm{C}$ & 419 & 422 & 422 & 420 & 421 & 422 \\
\hline & $T_{g, \text { out }}$ & ${ }^{\circ} \mathrm{C}$ & 400 & 400 & 400 & 400 & 400 & 400 \\
\hline & $p_{h p, s e p}$ & bar & 100 & 350 & - & 101 & 331 & - \\
\hline & $N_{s, H 2 O}$ & - & 5 & - & - & 5 & - & - \\
\hline & $r_{\mathrm{CH} 4, \mathrm{sel}}$ & $\%$ & - & 96.9 & 96.7 & - & 96.1 & 96.8 \\
\hline & $A_{\text {sel }}$ & - & - & 1.02 & 1.03 & - & 1.00 & 1.05 \\
\hline & $\tilde{c}_{C H 4, \text { sel }, \text { out }}$ & $\%$ & - & - & 94.0 & - & - & 94.1 \\
\hline & $y_{m e m b}$ & - & - & - & 2 & - & - & 2 \\
\hline & $y_{\text {prec }}^{v}$ & - & - & - & - & 1 & 1 & 1 \\
\hline & $y_{\text {prec }}^{l}$ & - & 1 & 1 & 1 & 1 & 1 & 1 \\
\hline & $T_{g, s}$ & ${ }^{\circ} \mathrm{C}$ & - & - & - & 592 & 317 & 589 \\
\hline & $p_{s, p}$ & bar & 49.9 & 47.3 & 28.1 & 45.5 & 31.8 & 21.8 \\
\hline & $T_{s, s}$ & ${ }^{\circ} \mathrm{C}$ & 506 & 502 & 438 & 500 & 488 & 503 \\
\hline & $T_{s, u}$ & ${ }^{\circ} \mathrm{C}$ & 141 & 163 & 130 & 134 & 163 & 102 \\
\hline & $p_{P O X}$ & bar & 6.4 & - & 18.7 & 9.5 & 12.6 & 16.4 \\
\hline & $y_{\text {fuel }}$ & - & 4 & - & 1 & 4 & 1 & 1 \\
\hline & $r_{f 1, H 2 O}$ & - & 0.02 & - & 0.01 & 0.13 & 0.09 & 0.01 \\
\hline & $r_{f 2, \mathrm{H} 2 \mathrm{O}}$ & - & 0.01 & - & - & 0.02 & - & - \\
\hline \multirow[t]{5}{*}{ Efficiencies } & $\varepsilon_{S N G}$ & $\%$ & 60.3 & 68.0 & 64.9 & 60.6 & 65.5 & 34.9 \\
\hline & $\varepsilon_{e l}$ & $\%$ & 7.2 & 3.3 & 3.3 & 7.1 & 5.4 & 24.2 \\
\hline & $\varepsilon$ & $\%$ & 67.5 & 71.3 & 68.3 & 67.7 & 70.9 & 59.1 \\
\hline & $\eta$ & $\%$ & 61.9 & 65.6 & 62.8 & 62.1 & 65.1 & 53.7 \\
\hline & $\varepsilon_{\text {chem }}$ & $\%$ & 72.9 & 73.9 & 70.8 & 73.1 & 74.9 & 77.4 \\
\hline \multirow[t]{4}{*}{ Costs $^{\mathrm{a}}$} & $c_{G R}$ & $\$ \mathrm{~kW}_{\text {biomass }}^{-1}$ & 900 & 2127 & 1585 & 938 & 2595 & 1355 \\
\hline & $C_{t o t}^{\mathrm{b}, \mathrm{c}}$ & $\$ \mathrm{MWh}_{\text {biomass }}^{-1}$ & 58.1 & 82.4 & 71.6 & 58.9 & 91.9 & 67.1 \\
\hline & $C_{c a t}$ & $\$ \mathrm{MWh}_{\text {biomass }}^{-1}$ & $5^{\prime} 651$ & 8’816 & $7 ’ 732$ & 6’895 & $7 ’ 377$ & 24 \\
\hline & $C_{\text {biomass }, \text { be }}{ }^{\mathrm{c}}$ & $\$ \mathrm{MWh}_{\text {biomass }}^{-1}$ & 60.2 & 38.1 & 45.2 & 59.6 & 29.4 & 51.3 \\
\hline
\end{tabular}

catalyst at lower temperatures decreases the maximum SNG yield by 5 points. If power recovery from the high pressure vapour phase is not possible since the turbine design may be technically unfeasible at small production scales [15], the most efficient solutions for the combined production are situated close to the top-end SNG generation at which the power consumption for a higher gas yield drastically increases (Fig. 2, left). In this range, partial oxidation gas turbines allow for a slightly higher marginal power yield $\Delta \dot{E}^{-} /\left(\Delta h_{S N G}^{0} \Delta \dot{m}_{S N G}^{-}\right)$than the benchmark efficiency $\eta_{N G C C}$ for a combined cycle. They are thus favoured in the configurations with maximum $\varepsilon_{\text {chem }}$ of Table 4 . If power recovery from the high pressure bulk phase is feasible (Fig. 2, right), a particularly high marginal efficiency for supplementary power generation is obtained at lower SNG rates. Combined with a partial oxidation gas turbine, configuration $(3 \mathrm{~m})$ reaches a second peak of the overall efficiency $\varepsilon_{\text {chem }}$ at relative yields of only $35 \%$ SNG, but $24 \%$ electricity. In this configuration and range, the performance is much less sensitive to the limitation of the catalyst kinetics that requires $T_{g, \text { out }} \geq 400^{\circ} \mathrm{C}$ and penalises the efficiency at high SNG yields. In general, the optimisation of the process design and its integration allows for increasing the equivalent 

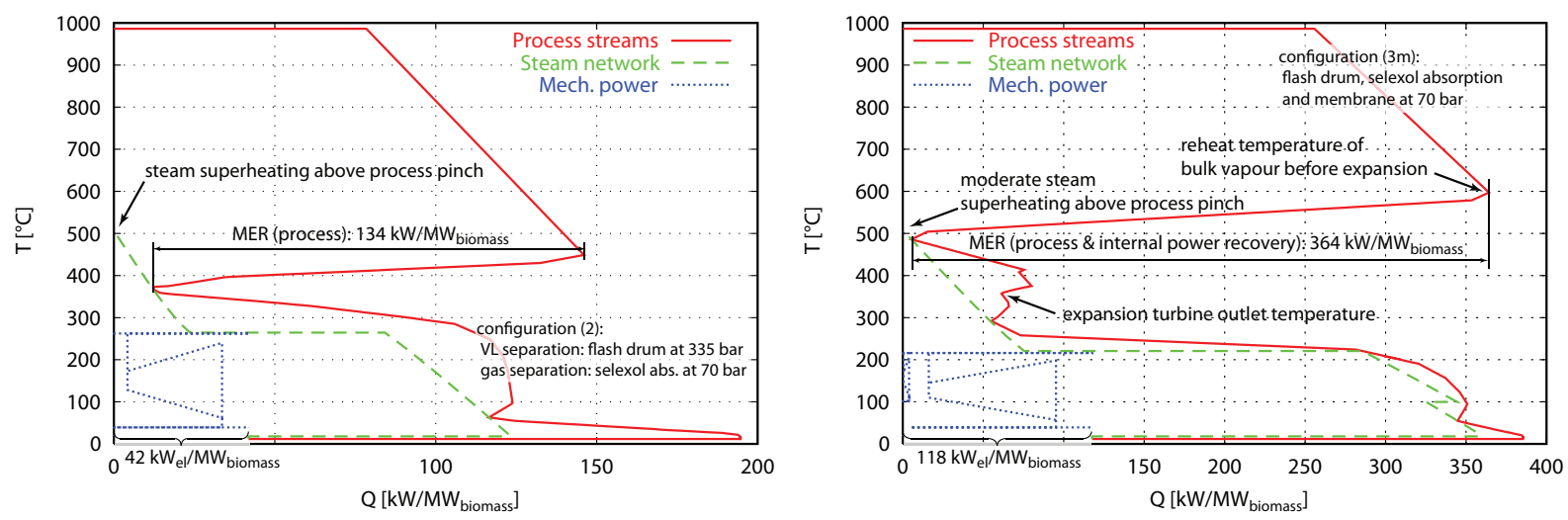

(a) without power recovery from the vapour phase at high pres-(b) with power recovery from the vapour phase at high pressure sure

Figure 3: Grand composite curves for the most efficient process configurations for wood feedstock

chemical efficiency by up to 4 to 9 points compared to the reference scenarios [3].

For the conceptual process design, some key variables can be identified from the decision variable distribution of the optimal configurations. In general, high pressure facilitates high SNG and chemical efficiency since it reduces the specific enthalpy requirement of the bulk water [1]. Decreasing pressure thus requires the combustion of more SNG to supply the minimum energy requirements (MER) of the process and emphasizes power cogeneration from the excess heat. The inverse effect is observed for the temperatures in the salt separator. Essentially determining the process pinch point and the heat requirement, low temperature is favourable for high SNG output, while high temperatures increase the share of cogenerated power. For the most efficient process design without power recovery from the crude product at high pressure, the composite curve in Figure 3(a) highlights that the optimisation of the process pressure and salt separation temperatures reduces the MER by $50 \%$ and the pinch point to $370 \mathrm{C}$ compared to the reference solution [3]. The use of a Rankine cycle with a condensation turbine allows for recovering $4 \%$ of the raw material's lower heating value as electrical power and results in a net power output $\varepsilon_{e l}$ of $3.3 \%$. If industrial heat can be used locally, $9 \%$ and $2.6 \%$ of the raw material's heating value could instead be cogenerated as heat at $110^{\circ} \mathrm{C}$ and power, respectively, which corresponds to an equivalent coefficient of performance of roughly 6 for the marginal substition of electricity by heat.

For separating the crude product in a water column, a very pronounced trend to the lower pressure limit (100 bar) confirms that high pressure mainly increases the pump power without being essential for the separation performance in the integrated system [3]. If a supplementary membrane separation step is used, relatively low methane purity in the high pressure column is further advantageous to limit the amount of additional water and thus the power required for pumping. Contrary to the VL and gas separation in a water column, high pressure is yet advantageous for pre-separating the crude product in a flash drum. The remaining decision variables for the separation system are not conflictive with respect to the relative output, but influence the thermo-economic trade-off discussed in Section 4.

In any case, power recovery from the high pressure streams increases the process efficiency. While liquid expanders appear mandatory if the gas is washed with water, power recovery from the vapour phase represents a major advantage if the entire bulk is expanded in the vapour phase and separated at grid pressure. Reheating across the pinch is thereby favourable in any case, although it slightly decreases the gas output by increasing the heat requirement. Combined with a topping partial oxidation turbine and a bottoming Rankine cycle, the composite curve of Figure 3(b) provides the characteristics of this efficient alternative with a high power share. In this setup, the partial oxidation turbine is preferably operated at 15 to 25 bar and fuelled by crude SNG without additional steam. For the Rankine cycle, moderate steam pressure or an organic working fluid is appropriate. In this most efficient configuration, $37 \%$ of the gross power yield is produced through internal recovery from the crude product at high pressure, $18 \%$ from the partial oxidation gas turbine and $45 \%$ in the Rankine cycle. If industrial heat can 
be used locally, the gross electricity production of $12 \%$ of the raw material's lower heating value by the Rankine cycle could be substituted by the combined production of $28 \%$ and $6 \%$ of heat at $110 \mathrm{C}$ and power, respectively, which corresponds to an equivalent coefficient of performance of roughly 5 .

\section{Optimal thermo-economic plant design}

\subsection{Problem setup}

Having explored the thermodynamic polygeneration potential of the hydrothermal conversion, the optimal thermo-economic plant design is addressed by considering the process economics [3]. In order to cover both the thermodynamic and economic design targets and allow for a clear analysis of the results, two consistently aggregated performance indicators are used as objectives. The chemical efficiency defined in Equation (7) represents the thermodynamic overall performance and covers all costs and profits directly linked to it (i.e. raw material, labour and returns from the products). With regard to the process economics, catalyst deactivation is of crucial importance and prevents the most efficient flowsheets of Table 4 to be economically feasible by orders of magnitude. In order to elaborate this particular impact on the process design and performance, separate optimisations with and without considering the cost for catalyst replacement in the process economics are carried out. In a first optimisation step (Section 4.2.1), catalyst poisoning by residual, dissolved sulphur that has not precipitated in the salt separator is considered by assuming that deactivated catalyst is disposed and replaced by new charges at full cost [3]. The purely economic aspects that are not directly linked to the energetic process inputs and outputs are thus represented by the specific investment cost plus the total catalyst cost over the whole plant lifetime, i.e. $c_{G R, c a t}$ as defined in Equation (10) is used as economic objective.

In order to provide a benchmark solution for comparing the impact of catalyst deactivation on the process design and performance, a second set of optimisations that disregards the catalyst cost is discussed in Section 4.2.2. This corresponds to the assumption that catalyst poisoning or its economic impact can be prevented by a chemical guard for the diluted sulphur or that its regeneration is possible at negligible cost. While the thermodynamic objective is identical to the previous case, only the specific investment cost $c_{G R}$ defined in Equation (8) is thus considered as economic objective.

In all these runs, the decision variables of Table 2, the use of wood feedstock and the distinct optimisation of flowsheets with and without power recovery from the vapour phase at high pressure are maintained.

\subsection{Results and discussion}

\subsubsection{With catalyst deactivation.}

The performance of the Pareto-optimal flowsheets for all process configurations considering full catalyst replacement cost are shown in Figure 4. Tables 5 and 6 summarise the economically optimal process configurations that maximise the biomass break-even costs $C_{\text {biomass, be }}$ (Eq. 9), and thus the process profitability, for flowsheets without and with power recovery from the high pressure vapour phase.

If power recovery from the vapour phase is not considered (Fig. 4(a) and (c)), VL separation in a high pressure flash drum and gas separation by physical absorption with Selexol dominate the Pareto domain at high efficiency (i.e. configuration $(2 \mathrm{~m})$ ). $\mathrm{CO}_{2}$ absorption in water $(1 \mathrm{~m})$ emerges as the best low-cost solution, and configurations without any separation at high pressure $(3 \mathrm{~m})$ are clearly suboptimal. An additional membrane separation stage is always advantageous since the residual equilibrium hydrogen content of $1.5-2.0 \% \mathrm{~mol}$ at $400^{\circ} \mathrm{C}$ is efficiently removed and the combustion of the depleted permeate supplies useful heat to the process. This allows for limiting the size of the bulk separation system without detrimental effect on the process efficiency due to process integration. At a plant capacity of $20 \mathrm{MW}_{\text {th,biomass }}$, configuration ( $1 \mathrm{~m}$ ) with gas pre-separation to $\tilde{c}_{C H 4, h p, o u t}=80 \%$ in a water absorption column with 3 equilibrium stages followed by the complete separation to grid quality with a polysulfone 

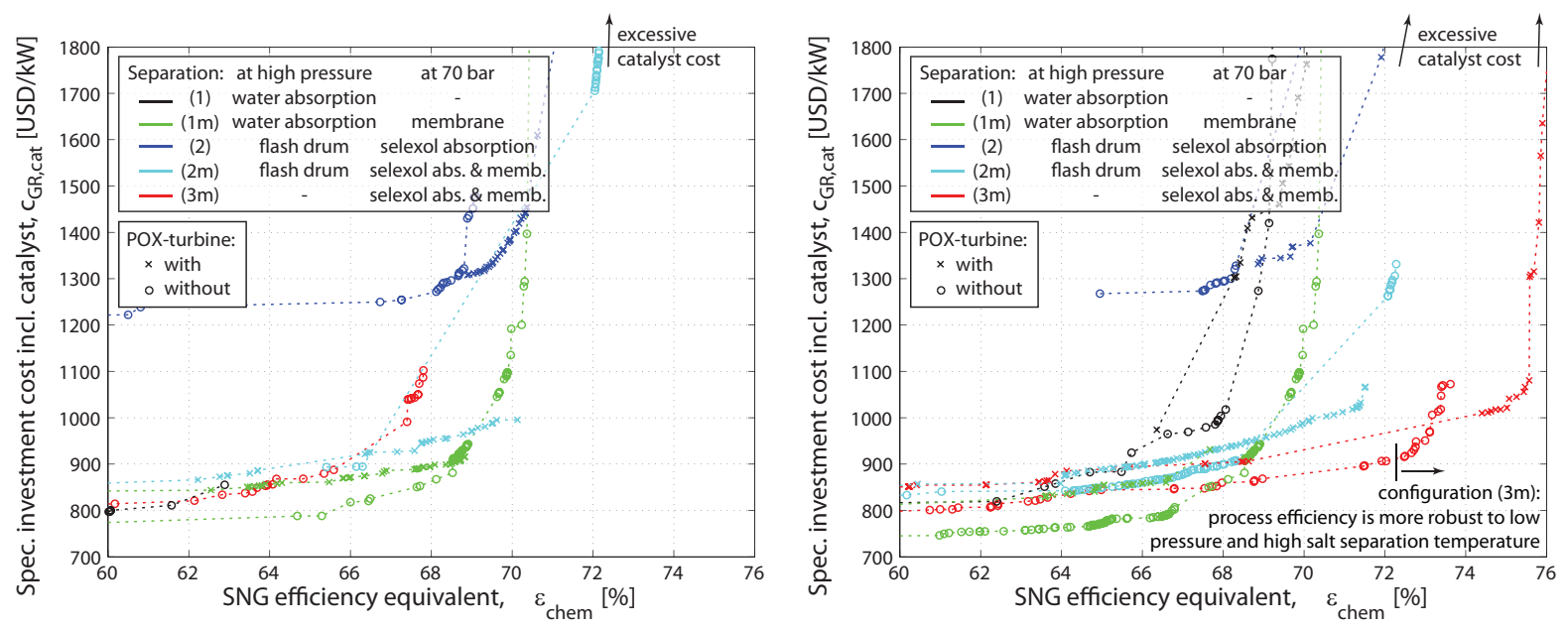

(a) Specific investment costs incl. catalyst vs. chemical ef-(b) Specific investment costs incl. catalyst vs. chemical effificiency (Pareto front) without power recovery from the high ciency (Pareto front) with power recovery from the high prespressure vapour phase

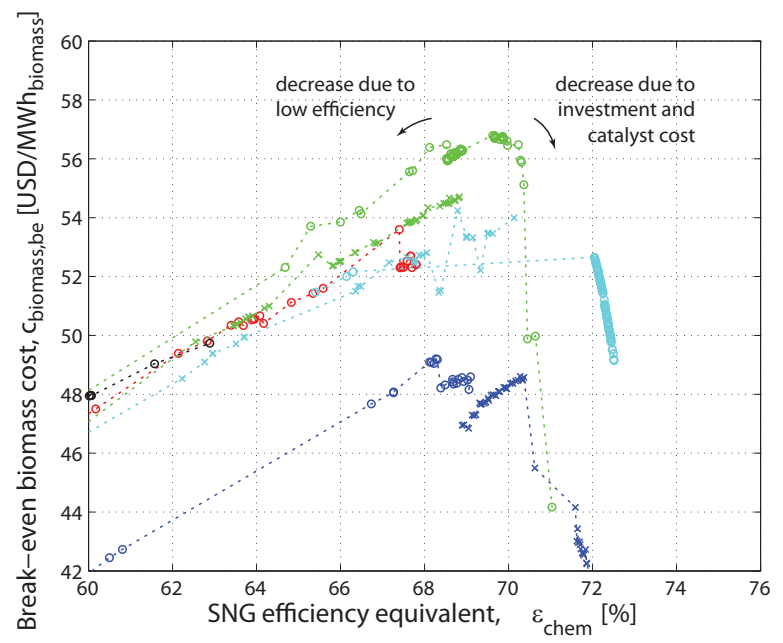
sure vapour phase

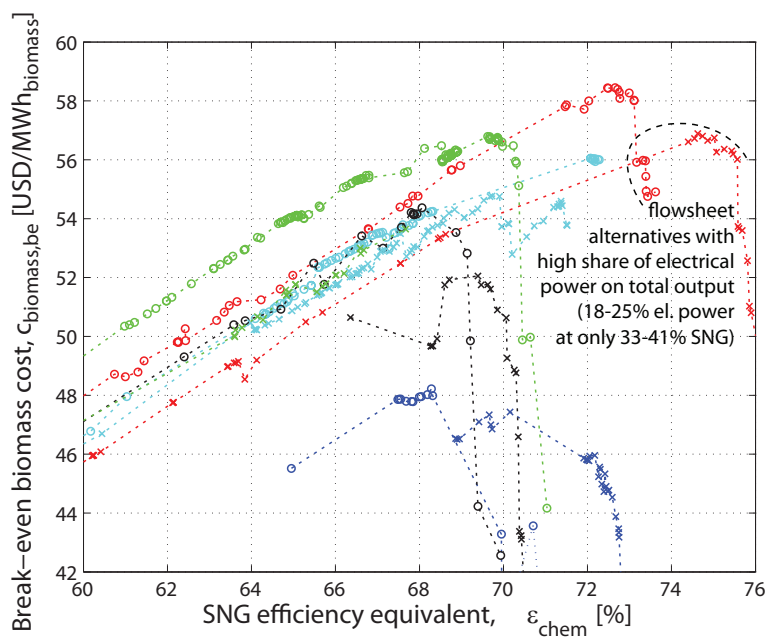

(c) Evolution of the biomass break-even cost on the Pareto front (d) Evolution of the biomass break-even cost on the Pareto front without power recovery from the high pressure vapour phase

with power recovery from the high pressure vapour phase

Figure 4: Optimal thermo-economic trade-off for wood feedstock and fully considering catalyst costs at $20 \mathrm{MW}_{\text {th } \text {,biomass. }}$. Dotted lines are for indication only

membrane emerges as the best compromise between efficiency and cost with respect to overall economic performance since it maximises $C_{\text {biomass, } b e}$ in Table 5 and Figure 4(c).

While power recovery from the vapour phase at high pressure has only a marginal impact on the process configurations with VL separation prior to expansion, it allows for increasing the combined efficiency by up to 8 points if the entire bulk phase is expanded. Configuration $(3 \mathrm{~m})$ thus clearly becomes the overall optimal solution of Figure 4(d) since it is the only one that allows for a significant power cogeneration at relatively modest SNG yields. Although in principle not more efficient than the other configurations (cf. Section 3), layout ( $3 \mathrm{~m}$ ) has the crucial advantage that its thermodynamic performance is more robust to design constraints imposed by the kinetic limitation of the catalyst and the need for keeping its deactivation at an acceptable level. According to the correlation that is used to estimate the mass flow of sulphur entering the reactor [34], the solubility of $\mathrm{Na}_{2} \mathrm{SO}_{4}$ increases markedly with pressure and decreases with temperature. Process efficiency, on the other hand, is favoured by high pressure and low salt separation temperature, and is thus highly conflictive with catalyst deactivation. As the catalyst cost is dominating the economically best solutions, all optimal configurations of Tables 5 and 6 that consider catalyst deactivation converge towards the minimum bound for the process pressure 
Table 5: Design variables and performance of the optimal process configurations for wood feedstock at $20 \mathrm{MW}_{\text {th,biomass }}$ with respect to break-even biomass costs without power recovery from the high pressure vapour phase

\begin{tabular}{|c|c|c|c|c|c|c|c|c|c|c|c|}
\hline \multirow{2}{*}{\multicolumn{2}{|c|}{$\begin{array}{c}\text { Catalyst deactivation } \\
\text { Unit } \\
\end{array}$}} & \multicolumn{5}{|c|}{ considered } & \multicolumn{5}{|c|}{ not considered } \\
\hline & & (1) & $(1 \mathrm{~m})$ & (2) & $(2 \mathrm{~m})$ & $(3 \mathrm{~m})$ & (1) & $(1 \mathrm{~m})$ & $(2)$ & $(2 \mathrm{~m})$ & $(3 \mathrm{~m})$ \\
\hline \multicolumn{12}{|c|}{ Design variables } \\
\hline$p_{t o t}$ & bar & 250 & 250 & 290 & 250 & 251 & 350 & 335 & 350 & 350 & 349 \\
\hline$T_{s s, \max }$ & ${ }^{\circ} \mathrm{C}$ & 543 & 501 & 550 & 540 & 524 & 430 & 467 & 430 & 439 & 441 \\
\hline$\Delta T_{s s, \text { int }}$ & ${ }^{\circ} \mathrm{C}$ & 40 & 70 & 37 & 64 & 70 & 10 & 61 & 10 & 32 & 30 \\
\hline$T_{\text {ss }, \text { out }}$ & ${ }^{\circ} \mathrm{C}$ & 503 & 431 & 513 & 476 & 454 & 420 & 407 & 420 & 407 & 412 \\
\hline$\Delta T_{s s, \text { bottom }}$ & ${ }^{\circ} \mathrm{C}$ & 41 & 62 & 69 & 66 & 56 & 70 & 68 & 70 & 63 & 69 \\
\hline$\Delta T_{s s, t o p}$ & ${ }^{\circ} \mathrm{C}$ & 67 & 30 & 62 & 58 & 26 & 19 & 58 & 22 & 26 & 28 \\
\hline$T_{g, i n}$ & ${ }^{\circ} \mathrm{C}$ & 400 & 400 & 411 & 400 & 400 & 422 & 420 & 422 & 422 & 422 \\
\hline$T_{g, \text { out }}$ & ${ }^{\circ} \mathrm{C}$ & 400 & 400 & 400 & 400 & 400 & 400 & 400 & 400 & 400 & 400 \\
\hline$p_{h p, s e p}$ & bar & 102 & 101 & 350 & 286 & - & 100 & 101 & 347 & 329 & - \\
\hline$N_{S, H 2 O}$ & - & 5 & 3 & - & - & - & 5 & 4 & - & - & - \\
\hline$\tilde{c}_{C H 4, h p, \text { out }}$ & $\%$ & - & 80.0 & - & - & - & - & 80.0 & - & - & - \\
\hline$r_{\mathrm{CH} 4, \mathrm{sel}}$ & $\%$ & - & - & 97.0 & 95.4 & 95.4 & - & - & 95.0 & 95.8 & 95.0 \\
\hline$A_{\text {sel }}$ & - & - & - & 1.61 & 1.41 & 1.32 & - & - & 1.46 & 1.18 & 1.21 \\
\hline$\tilde{c}_{C H 4, \text { sel,out }}$ & $\%$ & - & - & - & 90.2 & 90.8 & - & - & - & 90.0 & 90.1 \\
\hline$y_{m e m b}$ & - & - & 2 & - & 2 & 2 & - & 2 & - & 2 & 1 \\
\hline$y_{\text {prec }}^{l}$ & - & 1 & 1 & 1 & 1 & 1 & 1 & 1 & 1 & 1 & 1 \\
\hline$p_{s, p}$ & bar & 20.1 & 48.9 & 68.4 & 57.2 & 69.6 & 44.6 & 43.9 & 62.5 & 44.7 & 22.2 \\
\hline$T_{s, s}$ & ${ }^{\circ} \mathrm{C}$ & 530 & 505 & 550 & 540 & 550 & 495 & 490 & 537 & 522 & 420 \\
\hline$T_{s, u}$ & ${ }^{\circ} \mathrm{C}$ & 54 & 122 & 127 & 120 & 122 & 121 & 127 & 154 & 152 & 121 \\
\hline$p_{P O X}$ & bar & 23.9 & - & 19.3 & 21.1 & 8.3 & - & 11.6 & - & - & - \\
\hline$y_{\text {fuel }}$ & - & - & - & - & 2 & - & - & 1 & - & - & - \\
\hline$r_{f 1, \mathrm{H} 2 \mathrm{O}}$ & - & - & - & - & - & - & - & 0.07 & - & - & - \\
\hline$r_{f 2, H 2 O}$ & - & - & - & - & 0.25 & - & - & - & - & - & - \\
\hline \multicolumn{12}{|c|}{ Efficiencies } \\
\hline$\varepsilon_{S N G}$ & $\%$ & 47.8 & 55.7 & 47.5 & 49.3 & 52.4 & 64.7 & 64.2 & 64.2 & 64.5 & 65.6 \\
\hline$\varepsilon_{e l}$ & $\%$ & 8.6 & 7.9 & 11.8 & 11.1 & 8.5 & 3.8 & 4.3 & 4.7 & 4.5 & 2.2 \\
\hline$\varepsilon$ & $\%$ & 56.4 & 63.6 & 59.3 & 60.4 & 60.9 & 68.6 & 68.5 & 68.8 & 69.0 & 67.8 \\
\hline$\eta$ & $\%$ & 51.6 & 58.4 & 54.2 & 55.3 & 55.8 & 63.0 & 62.9 & 63.2 & 63.4 & 62.4 \\
\hline$\underline{\varepsilon_{\text {chem }}}$ & $\%$ & 62.9 & 69.6 & 68.3 & 68.8 & 67.4 & 71.5 & 71.7 & 72.4 & 72.3 & 69.5 \\
\hline \multicolumn{12}{|l|}{ Costs $^{\mathrm{a}}$} \\
\hline$c_{G R}$ & $\$ \mathrm{~kW}_{\text {biomass }}^{-1}$ & 754 & 718 & 953 & 831 & 789 & 677 & 650 & 805 & 778 & 720 \\
\hline$C_{t o t}^{\mathrm{b}, \mathrm{c}}$ & $\$ \mathrm{MWh}_{\text {biomass }}^{-1}$ & 55.2 & 54.5 & 59.1 & 56.7 & 55.8 & 53.6 & 53.2 & 56.3 & 55.7 & 54.5 \\
\hline$C_{\text {cat }}$ & $\$ \mathrm{MWh}_{\text {biomass }}^{-1}$ & 0.9 & 2.8 & 2.9 & 1.2 & 1.8 & 890 & 521 & 873 & 1’402 & 935 \\
\hline$C_{\text {biomass }, \text { be }}$ & $\$ \mathrm{MWh}_{\text {biomass }}^{-1}$ & 49.7 & 56.8 & 49.2 & 54.2 & 53.6 & -826 & -457 & -810 & $-1 ’ 339$ & -874 \\
\hline$C_{\text {biomass }, \text { be }}{ }^{\mathrm{c}}$ & $\$ \mathrm{MWh}_{\text {biomass }}^{-1}$ & 50.6 & 59.6 & 52.1 & 55.4 & 55.4 & 63.9 & 64.6 & 62.2 & 62.8 & 61.2 \\
\hline
\end{tabular}

and the maximum bound for the salt separation temperature, while the opposite is the case for those that disregard catalyst cost. Accordingly, superheating and expansion of the bulk is the unique flowsheet alternative that allows for very high process efficiency despite unfavourable process pressure and salt separation temperature.

Apart $p_{t o t}, T_{s s, \max }$ and $\Delta T_{s s, \text { int. }}$ that are governed by the influence of catalyst deactivation, the other decision variables are mainly subject to the conventional thermo-economic trade-off between investment and efficiency. The temperature differences for the heat transfer in the salt separator follow the classical compromise between cost for exchanger surface and energy efficiency. For the gas separation in a water column, an increasing number of equilibrium stages has a positive effect on the separation and process efficiency, but requires a higher investment. Gas posttreatment in a membrane separation stage thereby 
Table 6: Design variables and performance of the optimal process configurations for wood feedstock at $20 \mathrm{MW}_{\text {th,biomass }}$ with respect to break-even biomass costs with power recovery from the high pressure vapour phase

\begin{tabular}{|c|c|c|c|c|c|c|c|c|c|c|c|}
\hline \multirow{2}{*}{\multicolumn{2}{|c|}{$\begin{array}{c}\text { Catalyst deactivation } \\
\text { Unit } \\
\end{array}$}} & \multicolumn{5}{|c|}{ considered } & \multicolumn{5}{|c|}{ not considered } \\
\hline & & $(1)$ & $(1 \mathrm{~m})$ & (2) & $(2 \mathrm{~m})$ & $(3 \mathrm{~m})$ & (1) & $(1 \mathrm{~m})$ & (2) & $(2 \mathrm{~m})$ & $(3 \mathrm{~m})$ \\
\hline \multicolumn{12}{|c|}{ Design variables } \\
\hline$p_{\text {tot }}$ & bar & 250 & 250 & 293 & 250 & 250 & 347 & 346 & 348 & 345 & 315 \\
\hline$T_{s s, \max }$ & ${ }^{\circ} \mathrm{C}$ & 511 & 501 & 542 & 489 & 548 & 453 & 473 & 451 & 453 & 451 \\
\hline$\Delta T_{s s, \text { int }}$ & ${ }^{\circ} \mathrm{C}$ & 67 & 70 & 10 & 66 & 49 & 36 & 64 & 36 & 45 & 38 \\
\hline$T_{s s, \text { out }}$ & ${ }^{\circ} \mathrm{C}$ & 444 & 431 & 531 & 424 & 498 & 417 & 409 & 416 & 408 & 413 \\
\hline$\Delta T_{s s, \text { bottom }}$ & ${ }^{\circ} \mathrm{C}$ & 51 & 62 & 61 & 67 & 62 & 70 & 65 & 63 & 61 & 69 \\
\hline$\Delta T_{s s, t o p}$ & ${ }^{\circ} \mathrm{C}$ & 66 & 30 & 55 & 59 & 68 & 32 & 42 & 30 & 44 & 35 \\
\hline$T_{g, i n}$ & ${ }^{\circ} \mathrm{C}$ & 400 & 400 & 412 & 400 & 400 & 421 & 421 & 421 & 421 & 416 \\
\hline$T_{g, \text { out }}$ & ${ }^{\circ} \mathrm{C}$ & 400 & 400 & 400 & 400 & 400 & 400 & 400 & 400 & 400 & 400 \\
\hline$p_{h p, s e p}$ & bar & 149 & 101 & 350 & 350 & - & 100 & 105 & 350 & 350 & - \\
\hline$N_{S, H 2 O}$ & - & 5 & 3 & - & - & - & 5 & 4 & - & - & - \\
\hline$\tilde{c}_{C H 4, h p, \text { out }}$ & $\%$ & - & 80.0 & - & - & - & - & 80.4 & - & - & - \\
\hline$r_{\mathrm{CH} 4, \mathrm{sel}}$ & $\%$ & - & - & 97.7 & 95.7 & 95.1 & - & - & 95.8 & 95.0 & 95.1 \\
\hline$A_{\text {sel }}$ & - & - & - & 1.80 & 1.20 & 1.30 & - & - & 1.53 & 1.29 & 1.28 \\
\hline$\tilde{c}_{C H 4, \text { sel }, \text { out }}$ & $\%$ & - & - & - & 90.2 & 90.0 & - & - & - & 90.0 & 90.3 \\
\hline$y_{m e m b}$ & - & - & 2 & - & 2 & 2 & - & 2 & - & 2 & 2 \\
\hline$y_{\text {prec }}^{v}$ & - & 1 & 0 & 1 & 1 & - & 0 & 0 & 1 & 1 & - \\
\hline$y_{\text {prec }}^{l}$ & - & 1 & 1 & 1 & 1 & 1 & 1 & 1 & 1 & 1 & 1 \\
\hline$T_{g, s}$ & ${ }^{\circ} \mathrm{C}$ & 360 & 400 & 466 & 416 & 369 & 327 & 339 & 378 & 373 & 300 \\
\hline$p_{s, p}$ & bar & 68.6 & 48.9 & 57.8 & 61.8 & 27.8 & 25.9 & 41.6 & 45.6 & 44.8 & 20.1 \\
\hline$T_{s, s}$ & ${ }^{\circ} \mathrm{C}$ & 542 & 505 & 546 & 532 & 511 & 418 & 482 & 532 & 488 & 428 \\
\hline$T_{s, u}$ & ${ }^{\circ} \mathrm{C}$ & 121 & 122 & 127 & 138 & 154 & 50 & 121 & 128 & 122 & 120 \\
\hline$p_{P O X}$ & bar & - & - & - & - & - & - & 21.4 & - & - & - \\
\hline$y_{f u e l}$ & - & - & - & - & - & - & - & 1 & - & - & - \\
\hline$r_{f 1, H 2 O}$ & - & - & - & - & - & - & - & 0.06 & - & - & - \\
\hline \multicolumn{12}{|l|}{ Efficiencies } \\
\hline$\varepsilon_{S N G}$ & $\%$ & 53.3 & 55.7 & 45.8 & 55.9 & 48.1 & 65.4 & 64.7 & 64.3 & 64.8 & 64.2 \\
\hline$\varepsilon_{e l}$ & $\%$ & 8.4 & 7.9 & 12.8 & 9.2 & 14.0 & 3.2 & 4.0 & 5.0 & 4.8 & 3.8 \\
\hline$\varepsilon$ & $\%$ & 61.7 & 63.6 & 58.6 & 65.1 & 62.1 & 68.6 & 68.7 & 69.3 & 69.6 & 68.1 \\
\hline$\eta$ & $\%$ & 56.5 & 58.4 & 53.5 & 59.7 & 56.7 & 63.0 & 63.1 & 63.6 & 64.0 & 62.5 \\
\hline$\varepsilon_{\text {chem }}$ & $\%$ & 68.1 & 69.6 & 68.3 & 72.1 & 72.7 & 71.0 & 71.7 & 73.1 & 73.3 & 70.9 \\
\hline \multicolumn{12}{|l|}{$\operatorname{Costs}^{\mathrm{a}}$} \\
\hline$c_{G R}$ & $\$ \mathrm{~kW}_{\text {biomass }}^{-1}$ & 775 & 718 & 991 & 842 & 821 & 680 & 654 & 840 & 798 & 713 \\
\hline$C_{t o t} \mathrm{~b}, \mathrm{c}$ & $\$ \mathrm{MWh}_{\text {biomass }}^{-1}$ & 55.6 & 54.5 & 59.9 & 56.9 & 56.6 & 53.8 & 53.2 & 56.9 & 56.0 & 54.3 \\
\hline$C_{c a t}$ & $\$ \mathrm{MWh}_{\text {biomass }}^{-1}$ & 2.1 & 2.8 & 2.9 & 3.6 & 0.9 & 490 & 589 & 583 & 858 & 170 \\
\hline$C_{\text {biomass, be }}$ & $\$ \mathrm{MWh}_{\text {biomass }}^{-1}$ & 54.4 & 56.8 & 48.2 & 56.1 & 58.4 & -426.7 & -524.2 & -519.6 & -794.2 & -107.9 \\
\hline$C_{\text {biomass }, \text { be }}{ }^{\mathrm{c}}$ & $\$ \mathrm{MWh}_{\text {biomass }}^{-1}$ & 56.5 & 59.6 & 51.1 & 59.7 & 59.3 & 63.4 & 64.6 & 62.3 & 63.4 & 62.6 \\
\hline
\end{tabular}

reduces the importance of the separation performance and allows for a smaller tower. A similar trend is observed for the absorption factor used in the Selexol column model, with which both the investment cost and the separation efficiency are negatively correlated. The choice of the membrane material is slightly conflictive. Polysulfone is more selective with respect to hydrogen and thus more efficient, while cellulose acetate is more permeable and cheaper. In general, high product recovery in the separation section is secondary with respect to plant profitability since the depleted streams are used to supply the required heat. If absorptive and diffusive separation are combined, low purity after the first step is identified as optimal since the resulting elevated membrane permeate flowrates are not penalising. The pressure at which the crude gas is (pre-)separated is not influenced by process economics. As in the 

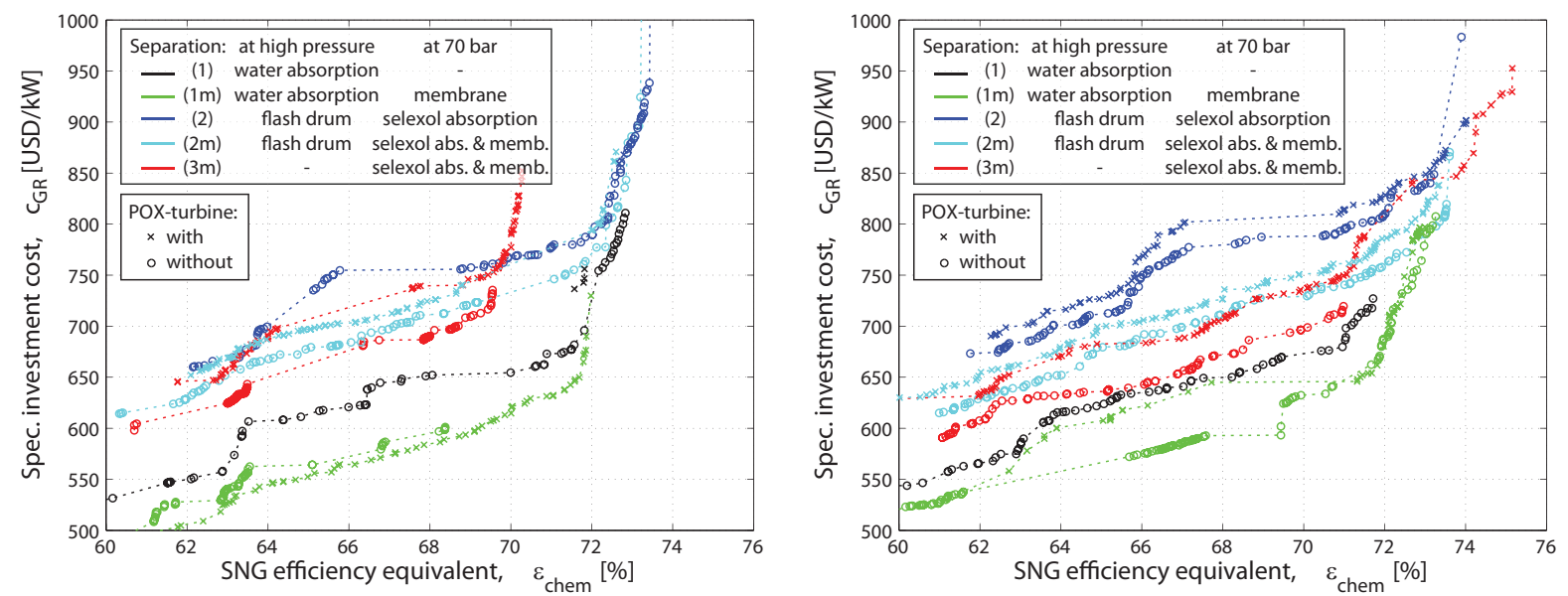

(a) Specific investment costs vs. chemical efficiency (Pareto (b) Specific investment costs vs. chemical efficiency (Pareto front) without power recovery from the high pressure vapour front) without power recovery from the high pressure vapour phase phase
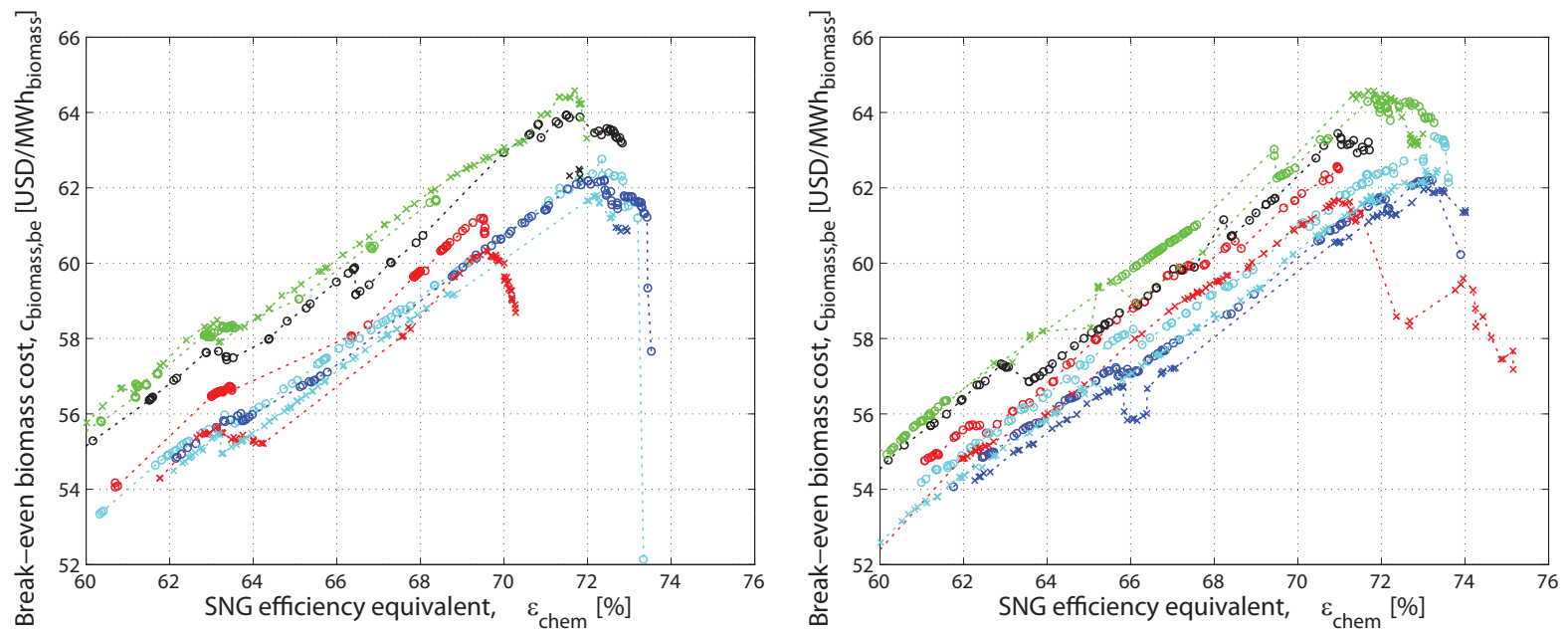

(c) Evolution of the biomass break-even cost on the Pareto front (d) Evolution of the biomass break-even cost on the Pareto front without power recovery from the high pressure vapour phase

with power recovery from the high pressure vapour phase

Figure 5: Optimal thermo-economic trade-off for wood feedstock without considering catalyst costs at $20 \mathrm{MW}_{\text {th,biomass }}$. Dotted lines are for indication only

previous section, it converges to its lower or higher limit if an absorption tower or flash drum is used, respectively.

Power recovery is always beneficial for high efficiency but requires some more investment. In a steam Rankine cycle, moderate steam generation pressure is sufficient since excess heat is available at relatively low temperature. Superheating slightly above the process pinch is rational, but the optimal temperature should match with the pressure. In any case, the investment for a partial oxidation turbine is not costeffective at the considered scale since the applied pricing slightly disfavours power generation compared to SNG by a lower economic than thermodynamic value.

\subsubsection{Without catalyst deactivation.}

In order to provide a benchmark solution for comparing the impact of catalyst deactivation on the process design, Figure 5 and the right parts of Tables 5 and 6 provide the results for a second set of optimisations that do not consider the cost for catalyst replacement. The optimisation setup is identical to the previous case, except that the specific investment $c_{G R}$ (Eq. 8) without catalyst cost is used as economic objective.

The thermo-economic characteristics of these flowsheet alternatives differ substantially from the ones 
that fully consider catalyst deactivation. The catalyst cost, or potential measures to prevent its fast poisoning by diluted sulphur, is thus crucially influencing the choice of the best process layout and its operating conditions. If an excessive deactivation or its economic impact can be prevented by other means than low process pressure and high separation temperature, the configurations $(3 \mathrm{~m})$ that superheat and expand the entire crude product without prior separation are less competitive since the alternatives with at least VL separation at high pressure do not suffer from these design constraints. While the performance of the former stagnates, the most profitable flowsheets that include a separation step at high pressure gain 2 to 4 points in terms of chemical efficiency. This is made possible by higher process pressure and lower maximum temperature that decrease the heat requirement and markedly shift the product distribution towards higher yields of SNG to the expense of cogenerated power (i.e. +8 to +18 points for $\varepsilon_{N G}$ compared to -4 to -8 points for $\varepsilon_{e l}$ ). This trend is even more pronounced if the catalyst kinetics allow for gasification below $400^{\circ} \mathrm{C}[15]$.

Although configuration (3m) still reaches the best top-end efficiency of all options (Fig. 5(b) and (d)), its high share of electricity on the yield distribution and the high investment cost are economically disfavoured by the assumed energy prices and the modest scale of $20 \mathrm{MW}_{t h \text {,biomass }}$. Configurations with $\mathrm{CO}_{2}$-absorption in water $((1)$ and $(1 \mathrm{~m}))$ dominate the Pareto domain over a large range and clearly emerge as the economically most competitive solution. The benefits of an additional membrane separation stage is less pronounced since higher gas yields can be obtained.

\subsection{Economic process scaling}

The most economic plant design and its performance is generally dependent on the production scale, and other configurations than those reported in Tables 5 and 6 may become optimal below or above $20 \mathrm{MW}_{\text {th,biomass. }}$. In order to determine the thermo-economic process scaling, it is valid to assume that the operating conditions within a set of Pareto-optimal flowsheets do not substantially change with process scale [15]. Hence, it is possible to select the optimal plant at any scale among the Pareto-optimal configurations whose investment cost is extrapolated from the reference scale. The influence of the process scale on the investment is conveniently expressed by a conventional cost exponent $b$ defined as:

$$
C_{G R}=C_{G R, \text { ref }}\left(\frac{\Delta h_{\text {biomass }}^{0} \dot{m}_{\text {biomass }, \text { daf }}^{+}}{\left(\Delta h_{\text {biomass }}^{0} \dot{m}_{\text {biomass }, \text { daf }}^{+}\right)_{\text {ref }}}\right)^{b}
$$

or, for a specific cost formulation:

$$
c_{G R}=c_{G R, r e f}\left(\frac{\Delta h_{\text {biomass }}^{0} \dot{m}_{\text {biomass }, \text { daf }}^{+}}{\left(\Delta h_{\text {biomass }}^{0} \dot{m}_{\text {biomass }, \text { daf }}^{+}\right)_{\text {ref }}}\right)^{(b-1)}
$$

Table 7 provides distinct values of $b$ for the major flowsheet configurations in the ranges [5 20] and [20 200] $\mathrm{MW}_{\text {th,biomass }}$ that can be used in conjunction with reference values for $c_{G R \text {, ref }}$ identified for a specific flowsheet on Figure 5 and Tables 5 and 6 . They have been obtained by regressing the exponent $b$ on the calculated values for $c_{G R}$ at 5, 10, 20, 50, 100 and $200 \mathrm{MW}_{t h, \text { biomass }}$ for all flowsheets of the Pareto fronts. With values in the range of 0.6 to 0.7 for inputs below $20 \mathrm{MW}_{t h \text {,biomass }}$ and higher than 0.8 above, substantial economies of scale are obtained from small- to mid-scale, but become less significant above roughly $50 \mathrm{MW}$. In general, they are greatest for the configurations with VL separation at high and gas separation at grid pressure (configurations (2)) and least for those with VL and gas separation in a high pressure water column (configurations (1)).

If catalyst deactivation is unavoidable and power recovery from the high pressure vapour phase infeasible, configuration $(1 \mathrm{~m})$ generates maximum profit over the entire range of 5 to $200 \mathrm{MW}_{\text {th,biomass }}$. If power recovery is feasible, the bulk expansion in the vapour phase of configuration $(3 \mathrm{~m})$ is best at and above $10 \mathrm{MW}_{\text {th, biomass }}$, and configuration $(1 \mathrm{~m})$ below. If catalyst costs can be disregarded and power recovery is not feasible, complete separation in a water column with configuration (1) is best at any scale. The same configuration with an additional membrane $(1 \mathrm{~m})$ is thereby more competitive if mechanical power is recovered from the bulk. 
Table 7: Regressed cost exponents $b$ for principal process configurations. The coefficient of determination $\mathrm{R}^{2}$ is higher than 0.95 if individual costs values at reference scale are allowed

\begin{tabular}{lcccccc}
\hline Range $\left[\mathrm{MW}_{\text {th }, \text { biomass }}\right]$ & \multicolumn{3}{c}{$[520]$} & & {$[20200]$} \\
Configuration & $(1)$ & $(2)$ & $(3)$ & $(1)$ & $(2)$ & $(3)$ \\
\hline Catalyst deactivation considered & 0.68 & 0.46 & 0.65 & 0.83 & 0.75 & 0.81 \\
Catalyst deactivation not considered & 0.69 & 0.64 & 0.66 & 0.85 & 0.82 & 0.83 \\
\hline
\end{tabular}

\section{Process optimisation for selected substrates}

In the previous sections, wood with the same properties as in a related work on SNG production by separate gasification and methanation has been used as reference feedstock to demonstrate the process design and provide a coherent assessment of its performance with respect to the more conventional pathway [13]. The process concept of hydrothermal gasification yet principally addresses the conversion of wet biomass and biomass waste, and relatively dry, clean and increasingly expensive wood is not the originally preferred feedstock. For this reason, the influence of the substrate properties on the process design and performance is discussed here for some representative examples.

\subsection{Candidate substrates}

Table 1 provides the relevant properties of a selection of candidate feedstocks for hydrothermal gasification. Among the potential substrates, sewage sludge and manure are abundant biomass wastes with a large potential [2]. Coffee grounds and lignin slurry represent typical energetically exploitable byproducts. While coffee grounds are an abundant food residue, large amounts of biomass are retrieved as slurries with high lignin content in the pulp and paper industry or in a future production of fuel ethanol from lignocellulosic biomass. In the latter case, excess heat from the SNG production might thereby also satisfy the requirement for the process (in particular, biomass pretreatment and ethanol distillation), and very favourable effects might emerge from process integration [21]. Finally, microalgae are considered as a photosynthetically efficient energy crop that are cultivable in photobioreactors on marginal land, from which a reduced environmental impact compared to land-based energy crops can be expected $[22,35]$.

Compared to wood, all these substrates offer a higher hydrogen fraction and thus an increased theoretical methane yield from the dry, ash-free substance according to Equation (1). Except coffee grounds and lignin slurry, they yet suffer from a higher ash content which reduces the effective biomass content if diluted to the same dry solids content. Among the substrates, manure has a particularly low solids content on an as-received basis and is the only substrate for which water purification by reverse osmosis is considered necessary.

\subsection{Optimisation problem setup}

As in the previous section, the process optimisation is addressed by first assessing the maximum potential for fuel and power cogeneration. A subsequent thermo-economic optimisation with and without considering catalyst cost and power recovery from the vapour phase of the crude gasification product at high pressure is then carried out. In addition to the decision variables outlined in Table 2, the choice of the separation subconfigurations (1)- $(3 \mathrm{~m})$ is left to the multi-objective algorithm in order to limit the computational time and data volume.

\subsection{Results and discussion}

Figure 6 provides the Pareto fronts of the overall best configurations for all substrates in the different optimisation steps.

The maximum partial efficiencies in Figure 6(a) and (b) assess a nearly equal cogeneration potential for coffee grounds, lignin slurry and wood. Microalgae, manure, undigested and digested sewage sludge 

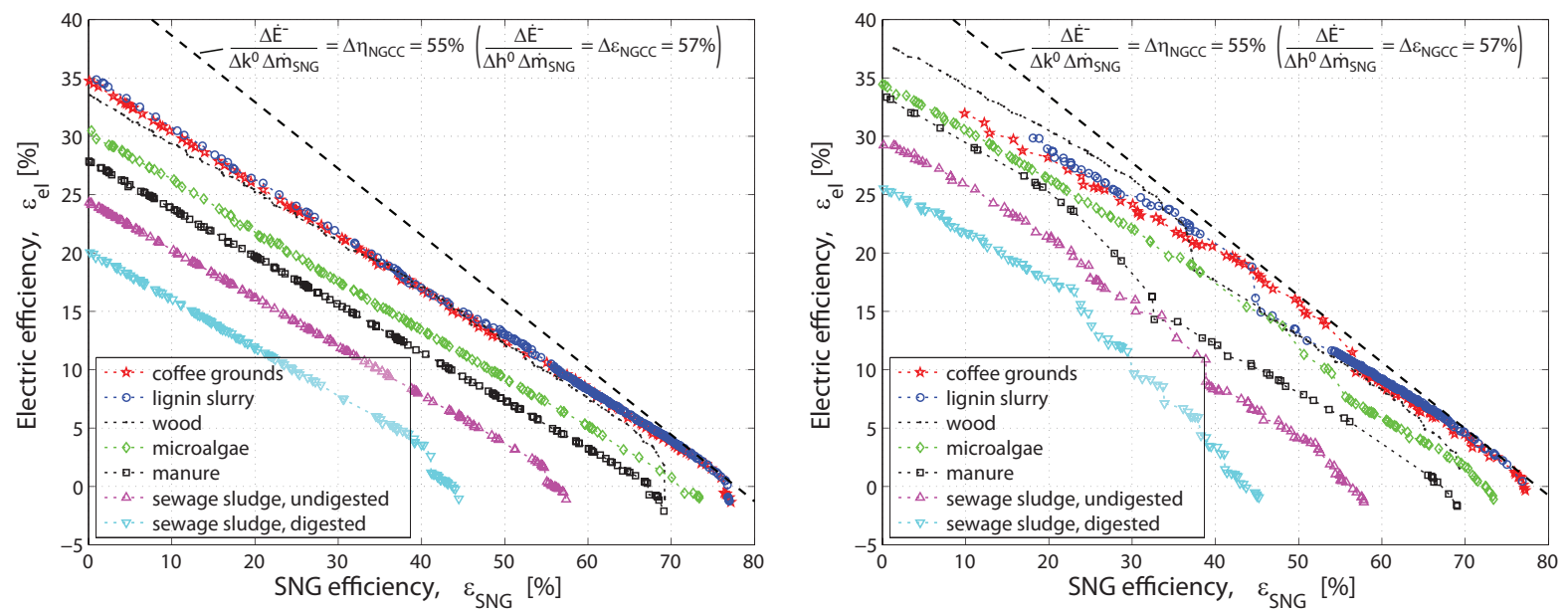

(a) Maximum partial efficiencies without power recovery from (b) Maximum partial efficiencies with power recovery from the the high pressure vapour phase

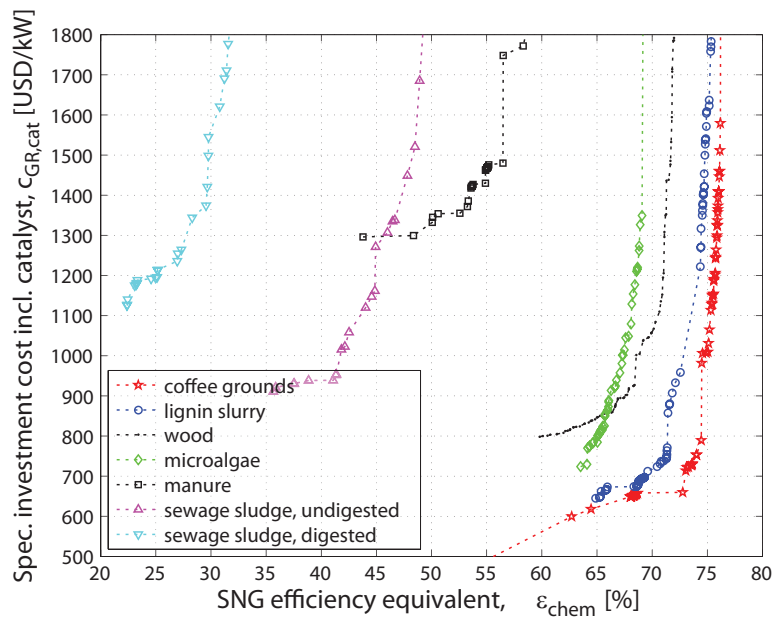
high pressure vapour phase

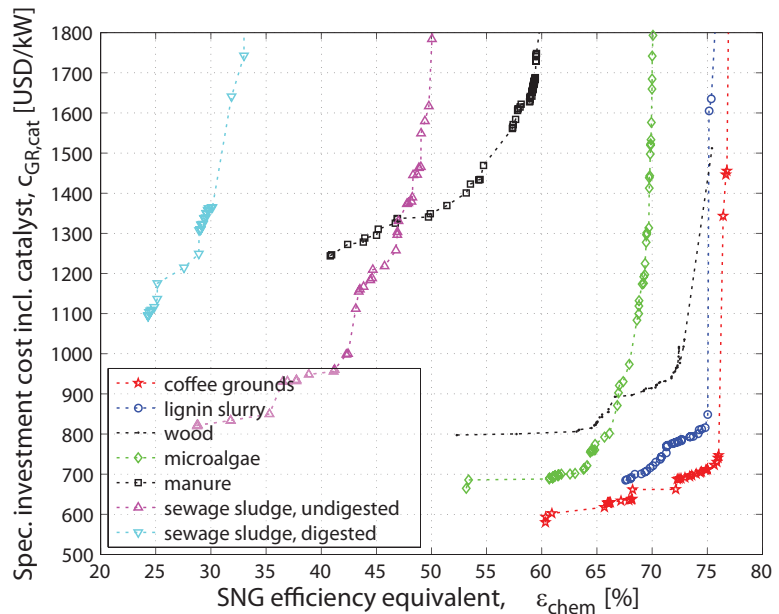

(c) Thermo-economic performance with full consideration of(d) Thermo-economic performance with full consideration of catalyst cost and without power recovery from the high pressure catalyst cost and with power recovery from the high pressure vapour phase vapour phase
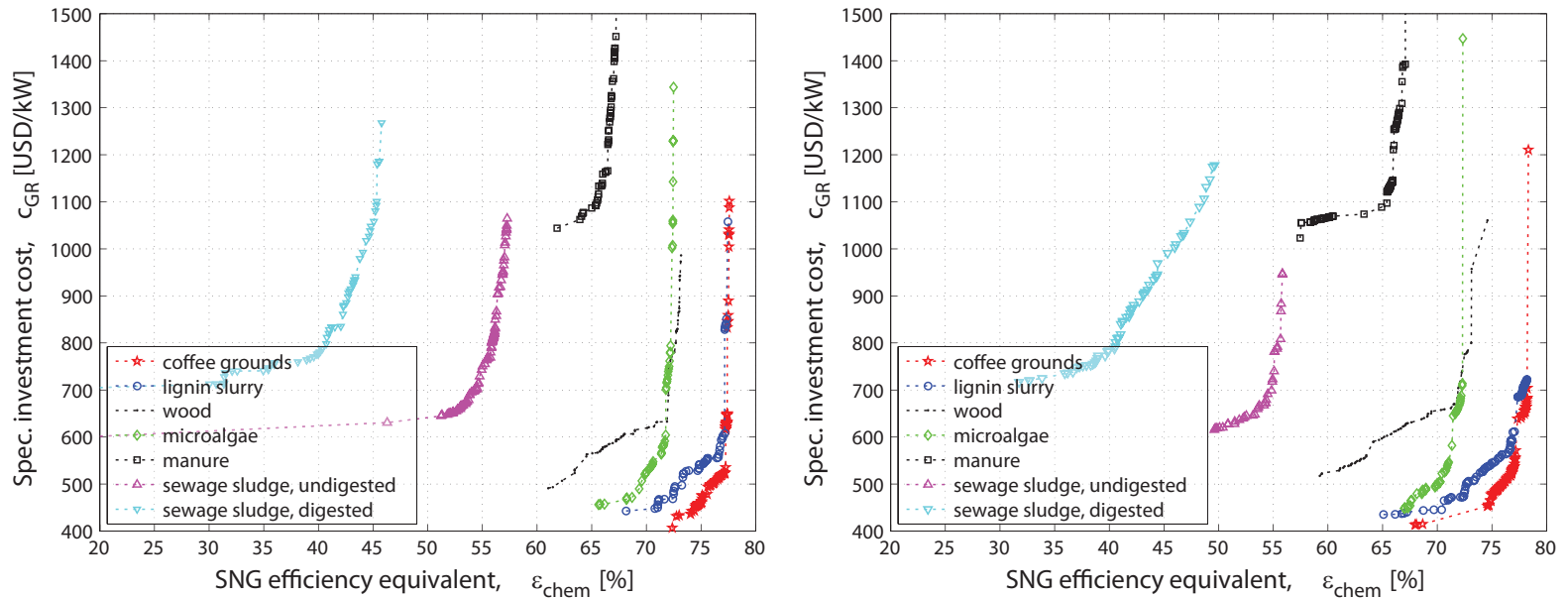

(e) Thermo-economic performance without catalyst deactiva-(f) Thermo-economic performance without catalyst deactivation and without power recovery from the high pressure vapourtion and with power recovery from the high pressure vapour phase

phase

Figure 6: Optimal thermodynamic and thermo-economic trade-off at $20 \mathrm{MW}_{\text {th,biomass. }}$. Dotted lines are for indication only 
perform consecutively worse. In comparison with Table 1, this order mainly follows the ash content of the substrates. With an equal total solids content of $20 \%$, the net dilution of the reactive biomass in water almost doubles in the worst case of digested sewage sludge and has a fatal impact on process efficiency since the amount of water to be entrained is doubled as well. Power recovery from the vapour phase at high pressure has a similar influence on the performance for all substrates as detailed for wood (Section 3). Since it allows for a high marginal efficiency in substituting the SNG production by electrical power generation, it provides an alternative set of highly efficient flowsheets that are situated at 20 to 40 points lower SNG yields than the first peak of chemical efficiency close to the maximum SNG yield.

These efficiency considerations have a big impact on the thermo-economic performance of the conversion. Compared to coffee grounds and lignin slurry which are dominating the common Pareto domain of Figures 6(c),(d) and 6(e),6(f), the conversion of wood is slightly less efficient and more expensive due to the higher $\mathrm{CO}_{2}$ share in the crude product that requires more effort for separation. Although potentially more efficient, it is thus competing with microalgae whose conversion is disfavoured by a slightly higher ash content. The waste substrates are clearly worst. Manure suffers from high investment cost for dewatering and especially waste water treatment by reverse osmosis. Sewage sludge is seriously penalised by its low thermodynamic performance due to the high effective dilution of the substrate. Due to a first removal of biodegradable matter by biomethanation, this penalty is considerably higher for digested than for undigested sludge. According to the available data [19], biomethanation converts $42 \%$ of the energy content of the dry, ash free raw sludge as methane. With an efficiency of up to 50-60\%, hydrothermal gasification of undigested sludge is more efficient since it converts the entire reactive part of the feedstock. The process yet consumes a considerable amount of the energy content of the substrate, and it is thus overall more efficient to hydrothermally gasify only the remaining undigestible part after a prior biological methane recovery at $42 \%$ efficiency. Despite the lower efficiency for the gasification of digested sludge in the order of 30 to $50 \%$, the combination of biological and thermochemical treatment reaches an overall efficiency of 60-70\%. Additional benefits from integrating hydrothermal gasification in waste water treatment plant can further be expected due to heat integration and the removal of nitrate in the thermochemical process, which has an important impact on the electricity consumption of traditional waste water plants [19].

Figure 7 illustrates the evolution of the process configuration on the thermo-economic Pareto fronts and clearly highlights that the optimal choice depends not only on the availability of energy conversion technology, catalyst deactivation and plant scale, but also on substrate properties. According to the trends observed in the detailed design study for wood, the use of a single separation technology is more efficient, but its combination with a membrane separation step is less costly since the purification requirement is relaxed. The flowsheets with absorption of $\mathrm{CO}_{2}$ in water thereby require less investment than Selexol, but are disfavoured at higher efficiency. If catalyst cost is considered and power recovery feasible, superheating and expansion of the bulk crude product emerges again as an interesting alternative since its efficiency is less sensible to the design constraints imposed to avoid excessive deactivation. For the economically best configurations, the yield distribution is similar to those obtained for wood. While an almost neutral power balance at high SNG yield seems best if catalyst deactivation does not need to be considered, converting up to $10 \%$ of the biomass input into power is more advantageous otherwise. The computed break-even costs for coffee waste, lignin slurry and microalgae are thereby similar to or higher than those of wood, which may result in considerably higher plant profitability if lower substrate prices apply. Although manure conversion suffers from high investment cost, such plants might yet be profitable since also low compensations for the feedstock can be expected. With the assumed inert fraction and dilution limit, the conversion of sewage sludge increases the energy efficiency of waste water treatment, but economical benefits should principally emerge from avoiding another type of waste treatment. 


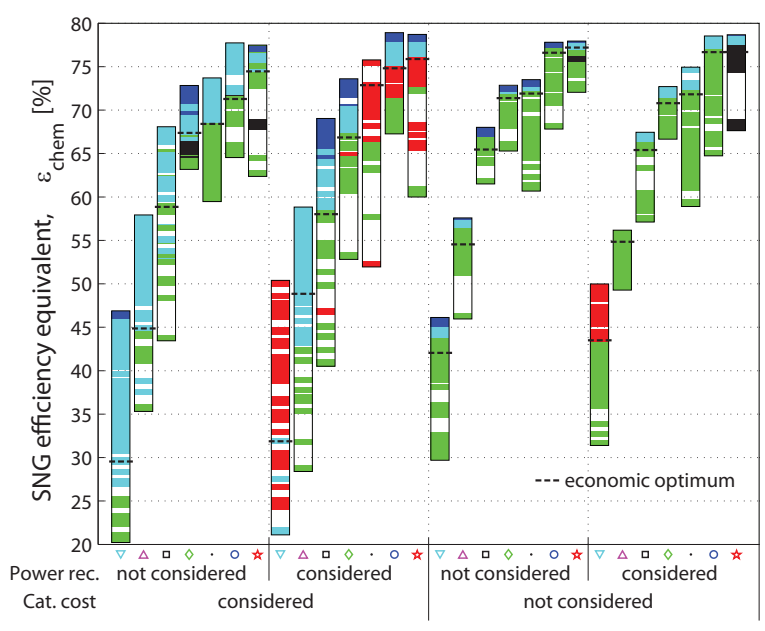

(a) Evolution of the best configuration on the Pareto front

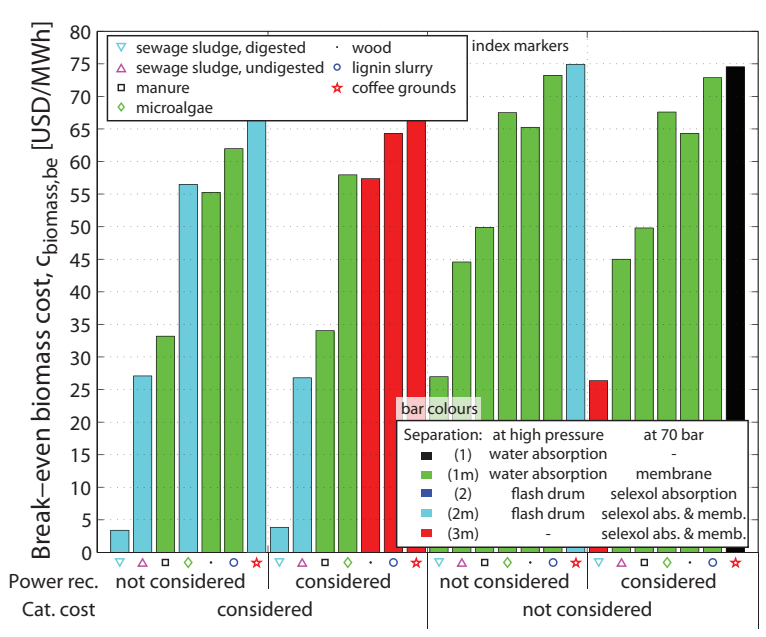

(b) Maximum biomass break-even cost of the most economic configuration at $20 \mathrm{MW}_{\text {th, biomass }}$

Figure 7: Characteristics of the best process configurations for the selected substrates

\section{Conclusions}

Based on a previously reported thermo-economic process model, this paper has presented a detailed design study for catalytic hydrothermal gasification of waste biomass in supercritical water. Using multiobjective optimisation techniques, the thermodynamic and thermo-economic trade-offs have been explored. The results show that an energetically and economically viable process can be designed even with conservative hypotheses on practical design limitations such as a maximum total solids content of $20 \%$ in the feed and the loss of $10 \%$ of the hydrolysate in the salt slurry. It has been shown that the hydrothermal conversion should thereby be regarded as an attractive polygeneration system in which SNG and electricity yields are to a large extent on a par. With overall chemical efficiencies of $70-77 \%$ in terms of SNG-equivalents for wood substrate, hydrothermal gasification is thereby even competitive with SNG production from dry biomass by conventional gasification and methanation that may reach up to $76-80 \%$ for wood at 50\% moisture [15]. In a detailed thermo-economic design study, it has been observed that catalyst deactivation and the availability of energy recovery technology crucially affect the process design and lead to solutions with substantially different characteristics. If catalyst deactivation or its economic impact can be avoided by other means than low pressure and high temperatures in the salt separator, flowsheets with gas and electricity yields around $65 \%$ and $4 \%$, respectively, are economically optimal. If excessive catalyst cost can only be avoided by keeping the salt solubility in the separator on a low level, substantially lower gas yields of 48 to $56 \%$ at an increased power cogeneration of 8 to $14 \%$ are more competitive since their overall efficiency is less sensitive to design constraints imposed to limit the catalyst deactivation at an acceptable level. Under these circumstances, superheating and expanding the bulk crude product proves as a particularly energy- and cost-efficient design alternative.

In the last part of the analysis, it is demonstrated that the process design and performance is not only influenced by available technology, catalyst deactivation and plant scale, but also by the characteristics of the processed substrate. Wet but energetically valuable industrial by-products with a high hydrogen and low ash content such as lignin slurries or coffee grounds have been identified as a particularly well suited feedstock that allow for greater efficiencies than wood. Biomass wastes with high ash content such as manure and sewage sludge are less advantageous since their effective biomass content is severely reduced if processing is limited to slurries containing no more than $20 \%$ total solids. From the perspective of waste treatment with disposal as principal objective, also marginal profit from a complete energy recovery from wastes might yet be valuable.

Overall, Table 8 shows that the sustainable Swiss biomass potential[2, 16] of $350-480 \mathrm{~W} \mathrm{cap}^{-1}$ might 
Table 8: Potentials for SNG production from biomass

\begin{tabular}{|c|c|c|c|c|c|}
\hline \multirow[b]{3}{*}{ Feedstock } & \multicolumn{2}{|c|}{ Biomass pot. ${ }^{\mathrm{a}}$} & \multirow{3}{*}{$\begin{array}{c}\mathcal{E}_{\text {chem }} \\
\text { (Fig. 7) } \\
\%\end{array}$} & \multicolumn{2}{|c|}{ eq. SNG yield } \\
\hline & $\mathrm{CH}[2]$ & $\mathrm{CH}[16]$ & & $\mathrm{CH}[2]$ & $\mathrm{CH}[16]$ \\
\hline & \multicolumn{2}{|c|}{$\mathrm{W} \mathrm{cap}^{-1}$} & & \multicolumn{2}{|c|}{$\mathrm{W} \operatorname{cap}^{-1}$} \\
\hline$\overline{\text { Wood }}$ & 161 & 327 & $68-75$ & $109-121$ & $222-245$ \\
\hline Sewage sludge & 22 & 26 & $60-70$ & $13-15$ & 16-18 \\
\hline Manure & 92 & 98 & $45-68$ & $41-63$ & $44-67$ \\
\hline Coffee grounds & 35 & 32 & $75-78$ & $26-27$ & $24-25$ \\
\hline Lignin slurry & 40 & 57 & $72-78$ & $29-31$ & $41-45$ \\
\hline Total & 350 & 540 & $62-74$ & $218-257$ & $347-400$ \\
\hline
\end{tabular}

${ }^{a}$ for a population of approx. 7.4 Mio (2005). Distribution to substrates is based loosely on the reported categories

be converted into an equivalent amount of $220-400 \mathrm{~W} \mathrm{cap}^{-1}$ of SNG with the optimally designed hydrothermal gasification plants of Figure $7^{2}$. This represents $43-78 \%$ of the country's natural gas consumption of $510 \mathrm{~W} \mathrm{cap}^{-1}$ (2005)[37] and would require an investment of 350-480 \$ cap ${ }^{-1}$ based on a specific cost of $1000 \$ \mathrm{~kW}_{\text {biomass }}^{-1}$ (or 36-49 $\$$ cap $^{-1}$ year $^{-1}$ discounted over 15 years). By substituting fossil natural gas, the national $\mathrm{CO}_{2}$ emissions would be reduced by approximately $8-14 \%$, or even $13-24 \%$ if the SNG would fuel state-of-the-art hybrid cars that replace the average Swiss car flee? ${ }^{3}$.

\section{Acknowledgements}

We thank Belsim SA [10] for their support to integrate our customised thermodynamic property model for the supercritical gas mixture in their software. Funding provided by the Competence Centre for Energy and Mobility (CCEM-CH), Erdgas Ostschweiz AG, Gasverbund Mittelland AG and Gaznat SA (all Switzerland) is greatfully acknowledged.

\section{References}

[1] F. Vogel, M. H. Waldner, A. A. Rouff, and S. Rabe. Synthetic natural gas from biomass by catalytic conversion in supercritical water. Green Chemistry, 9(6):616-619, 2007.

[2] B. Steubing, R. Zah, P. Waeger, and C. Ludwig. Bioenergy in Switzerland: Assessing the domestic sustainable biomass potential. Renewable and Sustainable Energy Reviews, 14(8):2256-2265, 2010. doi: 10.1016/j.rser.2010.03.036.

[3] Martin Gassner, Frédéric Vogel, Georges Heyen, and François Maréchal. Optimal process design for the polygeneration of SNG, power and heat by hydrothermal gasification of waste biomass: Thermo-economic process modelling and integration. Energy and Environmental Science, page in press, 2011. doi: 10.1039/C0EE00629G.

[4] M. H. Waldner, F. Krumeich, and F. Vogel. Synthetic natural gas by hydrothermal gasification of biomass. Selection procedure towards a stable catalyst and its sodium sulfate tolerance. Journal of Supercritical Fluids, 43(1):91-105, 2007.

[5] A. A. Peterson, P. Vontobel, F. Vogel, and J. W. Tester. In situ visualization of the performance of a supercritical-water salt separator using neutron radiography. Journal of Supercritical Fluids, 43 (3):490-499, 2008.

\footnotetext{
${ }^{2}$ The worldwide potential is estimated between 100-400 $\mathrm{EJ}_{\text {year }}{ }^{-1}$ [36], which corresponds to $490-1940 \mathrm{~W} \mathrm{cap}^{-1}$ of biomass that could supply $300-1440 \mathrm{~W} \mathrm{cap}^{-1}$ of SNG to a population of 6.5 billion people

${ }^{3}$ calculation basis: $\mathrm{CO}_{2}$ emissions of Switzerland (2005)[37]: $5.2 \mathrm{t} \mathrm{cap}^{-1}$ year $^{-1}$; Substituted emissions for natural gas (combustion only, i.e. transport neglected) [38]: $203 \mathrm{~g}_{C O 2 e q} \mathrm{kWh}^{-1}$; car emission: Swiss fleet average: $180 \mathrm{~g}_{C O 2 e q} \mathrm{~km}^{-1}$, state-of-the-art NG hybrid[39]: $105 \mathrm{~g}_{\mathrm{CO} 2 \mathrm{eq}} \mathrm{km}^{-1}$
} 
[6] A. A. Peterson, P. Vontobel, F. Vogel, and J. W. Tester. Normal-phase dynamic imaging of supercritical-water salt precipitation using neutron radiography. Journal of Supercritical Fluids, 49(1):71-78, 2009.

[7] Martin Schubert, Johann W. Regler, and Frédéric Vogel. Continuous salt precipitation and separation from supercritical water. Part 1: Type 1 salts. Journal of Supercritical Fluids, 52:99-112, 2010.

[8] Martin Schubert, Johann W. Regler, and Frédéric Vogel. Continuous salt precipitation and separation from supercritical water. Part 2: Type 2 salts and mixture of two salts. Journal of Supercritical Fluids, 52:113-124, 2010.

[9] Martin Gassner and François Maréchal. Methodology for the optimal thermo-economic, multiobjective design of thermochemical fuel production from biomass. Computers and Chemical Engineering, 33:769-781, 2009.

[10] Belsim SA. Vali IV. www.belsim.com, last visited 04/2009.

[11] Martin Gassner and François Maréchal. Combined mass and energy integration in process design at the example of membrane-based gas separation systems. Computers and Chemical Engineering, 34(12):2033-2042, 2010. Invited publication for the special edition of PSE 2009.

[12] A. Molyneaux, G. Leyland, and D. Favrat. Environomic multi-objective optimisation of a district heating network considering centralized and decentralized heat pumps. Energy, 35(2):751-758, 2010 .

[13] Martin Gassner and François Maréchal. Thermo-economic process model for thermochemical production of Synthetic Natural Gas (SNG) from lignocellulosic biomass. Biomass and Bioenergy, 33: 1587-1604, 2009. doi: 10.1016/j.biombioe.2009.08.004.

[14] Martin Gassner, Renato Baciocchi, François Maréchal, and Marco Mazzotti. Integrated design of a gas separation system for the upgrade of crude SNG with membranes. Chemical Engineering and Processing: Process Intensification, 48:1391-1404, 2009.

[15] Martin Gassner. Process design methodology for thermochemical production of fuels from biomass. Application to the production of Synthetic Natural Gas from lignocellulosic resources. $\mathrm{PhD}$ thesis, EPFL, 2010. doi: 10.5075/epfl-thesis-4693.

[16] B. Oettli, M. Blum, M. Peter, O. Schwank, D. Bedniaguine, E. Gnansounou, J. Chételat, F. Golay, J.-L. Hersener, U. Meier, and K. Schleiss. Potenziale zur energetischen Nutzung von Biomasse in der Schweiz. Schlussbericht. Technical report, Bundesamt für Energie, Bern, 2004.

[17] Maurice Henri Waldner. Catalytic hydrothermal gasification of biomass for the production of synthetic natural gas. PhD thesis, Eidgenössische Technische Hochschule Zürich, 2007.

[18] F. Maréchal, D. Favrat, and E. Jochem. Energy in the perspective of the sustainable development: The $2000 \mathrm{~W}$ society challenge. Resources, Conservation and Recycling, 44(3 spec. iss.):245-262, 2005.

[19] N. Desoins, S. Deleris, R. Lestienne, and F. Maréchal. Energetic efficiency in waste water treatment plants: Optimization of activated sludge process coupled with anaerobic digestion. In 23th International conference on efficiency, cost, optimization, simulation and environmental impact of energy systems (ECOS), 2010.

[20] ECN. Phyllis, database for biomass and waste. www.ecn.nl/phyllis, last visited 06/2009. 
[21] Suping Zhang, François Maréchal, Martin Gassner, Zoé Périn-Levasseur, Wei Qi, Zhengwei Ren, Yongjie Yan, and Daniel Favrat. Process modeling and integration of fuel ethanol production from lignocellulosic biomass based on double acid hydrolysis. Energy and Fuels, 23:1759-1765, 2009.

[22] A. G. Haiduc, M. Brandenberger, S. Suquet, F. Vogel, R. Bernier-Latmani, and C. Ludwig. SunCHem: An integrated process for the hydrothermal production of methane from microalgae and $\mathrm{CO}_{2}$ mitigation. Journal of Applied Phycology, 21(5):529-541, 2009.

[23] EPFL Pleiades cluster. pleiades.epfl.ch, last visited 11/2009.

[24] Z. Duan, N. Møller, and J. H. Weare. An equation of state for the $\mathrm{CH}_{4}-\mathrm{CO}_{2}-\mathrm{H}_{2} \mathrm{O}$ system: I. Pure systems from 0 to $1000^{\circ} \mathrm{C}$ and 0 to 8000 bar. Geochimica et Cosmochimica Acta, 56:2605-2617, 1992.

[25] Z. Duan, N. Møller, and J. H. Weare. An equation of state for the $\mathrm{CH}_{4}-\mathrm{CO}_{2}-\mathrm{H}_{2} \mathrm{O}$ system: II. Mixtures from 50 to $1000^{\circ} \mathrm{C}$ and 0 to 1000 bar. Geochimica et Cosmochimica Acta, 56:2619-2631, 1992.

[26] Byung I. Lee and Michael G. Kesler. Generalized thermodynamic correlation based on threeparameter corresponding states. AIChE Journal, 21(3):510-527, 1975.

[27] Gregory Esser and Georges Heyen. Étude thermodynamique d'un procédé de gazéification de biomass à pression élevée. Master's thesis, Université de Liège, 2008.

[28] Z. Duan and R. Sun. An improved model calculating $\mathrm{CO}_{2}$ solubility in pure water and aqueous $\mathrm{NaCl}$ solutions from 273 to $533 \mathrm{~K}$ and from 0 to 2000 bar. Chemical Geology, 193:257-271, 2003.

[29] Z. Duan and S. Mao. A thermodynamic model for calculating methane solubility, density and gas phase composition of methane-bearing aqueous fluids from 273 to $523 \mathrm{~K}$ and from 1 to 2000 bar. Geochimica et Cosmochimica Acta, 70:3369-3386, 2006.

[30] J. Qin, R. J. Rosenbauer, and Z. Duan. Experimental measurements of vapor-liquid equilibria of the $\mathrm{CH}_{4}-\mathrm{CO}_{2}-\mathrm{H}_{2} \mathrm{O}$ ternary system. Journal of Chemical and Engineering Data, 53:1246-1249, 2008.

[31] Werner Boie. Fuel technology calculations. Energietechnik, 3:309-316, 1953.

[32] J. Szargut and T. Styrylska. Angenäherte Bestimmung der Exergie von Brennstoffen. BrennstoffWärme-Kraft, 16:589-636, 1964.

[33] D. Favrat, F. Marechal, and O. Epelly. The challenge of introducing an exergy indicator in a local law on energy. Energy, 33(2):130-136, 2008.

[34] Ingo Leusbrock, Sybrand J. Metz, Glenn Rexwinkel, and Geert F. Versteeg. Quantitative approaches for the description of solubilities of inorganic compounds in near-critical and supercritical water. Journal of Supercritical Fluids, 47:117-127, 2008.

[35] S. Stucki, F. Vogel, C. Ludwig, A. G. Haiduc, and M. Brandenberger. Catalytic gasification of algae in supercritical water for biofuel production and carbon capture. Energy and Environmental Science, 2(5):535-541, 2009.

[36] G. Berndes, M. Hoogwijk, and R. van den Broek. The contribution of biomass in the future global energy supply: a review of 17 studies. Biomass and Bioenergy, 25:1-28, 2003.

[37] BFE. Schweizerische Gesamtenergiestatistik. Bundesamt für Energie, Bern, 2005.

[38] Ecoinvent database. Swiss Centre for Life Cycle Inventories. www.ecoinvent.org.

[39] R. Edwards, J-C. Griesemann, J-F. Larivé, and V. Mathieu. Well-to-wheels analysis of future automotive fuels and powertrains in the european context. well-to-wheels report. EUCAR/CONCAWE, January 2004. Version 1 b. 